\title{
Silica-Titania Composite (STC)'s Performance in the Photocatalytic Oxidation of Polar VOCs
}

\author{
Lanfang H. Levine', Janelle L. Coutts ${ }^{2}$, and Jeffrey T. Richards ${ }^{3}$ \\ Engineering Support Contract-Team QNA, Kennedy Space Center, FL 32899, USA \\ and \\ David Mazyck \\ Department of Environmental Engineering Sciences, University of Florida, Gainesville, FL \\ 32611, USA
}

\begin{abstract}
The objective of this paper is to determine the performance of a Silica-Titania Composite (STC) in the photocatalytic oxidation (PCO) of polar VOCs for potential applications in trace contaminant control within space habitats such as the ISS and CEV Orion. Tests were carried out in a bench scale STC-packed annular reactor under continuous illumination by either a UV-C germicidal lamp $\left(\lambda_{\max }=254 \mathrm{~nm}\right)$ or UV-A fluorescent BLB $\left(\lambda_{\max }=365 \mathrm{~nm}\right)$ for the removal of ethanol (a predominant polar VOC in the ISS cabin). The STC's performance was evaluated in terms of the ethanol mineralization rate, mineralization efficiency, and the extent of its oxidation intermediate (acetaldehyde) formation in response to the type of light source (photon energy and photon flux) and relative humidity (RH) implemented. Results demonstrated that acetaldehyde was the only quantifiable intermediate in the effluent under UV illumination, but was not found in the dark adsorption experiments. The mineralization rate increased with an increase in photon energy (UV-C > UV-A), even though both lamps were adjusted to emit the same incident photon flux, and also increased with increasing photon flux. However, photonic efficiency decreased as the photon flux increased. More importantly, a higher photon flux gave rise to a lower effluent acetaldehyde concentration. The effect of RH on PCO was complex and intriguing because it affected both physical adsorption and photocatalytic oxidation. In general, increasing RH caused a decrease in adsorption capacity for ethanol and reduced the mineralization efficiency with a concomitant higher acetaldehyde evolution rate. The effect of RH was less profound than that of photon flux.
\end{abstract}

\section{Nomenclature}

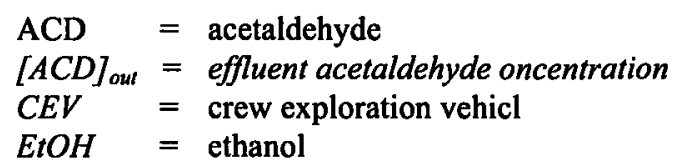

${ }^{1}$ Senior Research Chemist, Entereprise Advisory Services, Inc. (a teammate of ESC-Team QNA), Mail Code: ESC-53, Kennedy Space Center, FL 32899 and AIAA senior member.

${ }^{2}$ Research Scientist, Applied Geo Technoligies, (a teammate of ESC-Team QNA), and graduate student in the Department of Chemistry, University of Central Florida, Orlando, FL32816

3 Research Chemist, Stinger Ghaffarian Technologies (a teammate of ESC-Team QNA), Mail Code: ESC-53, Kennedy Space Center, FL 32899.

${ }^{4}$ Professor, Department of Environmental Engineering Sciences, University of Florida, Gainesville, FL32611, and AIAA senior member. 




\section{Introduction}

$\mathrm{T}$ itanium dioxide $\left(\mathrm{TiO}_{2}\right)$-catalyzed UV photocatalytic oxidation $(\mathrm{PCO})$ is one of the alternative trace contaminant control technologies currently under evaluation for applications in air revitalization for future NASA programs. It has also been proposed for a niche application in the removal of polar organic contaminants from air streams prior to a condensing heat exchanger in order to alleviate the burden of processing condensate water. ${ }^{1}$ The greatest advantage of this technology over traditional thermal catalytic oxidation (TCO) lies in its low energy demand because it breaks down a broad range of organic contaminants into $\mathrm{CO}_{2}$ and $\mathrm{H}_{2} \mathrm{O}$ at room temperature. However, one of the major concerns over this technology is its potential for incomplete oxidation, resulting in the formation and accumulation of intermediates (e.g., formaldehyde, acetaldehyde) more toxic than the original contaminants. ${ }^{2-3}$ In order to address this concern, increasing the intrinsic photocatalytic activity of photocatalysts and optimizing reactor design have been the subjects of much research. It is known that the photocatalytic activity of $\mathrm{TiO}_{2}$ strongly depends on the efficiency of electron-hole separation (reduction and/or elimination of the electron-hole recombination) as well as the adsorption ability of gaseous volatile organic compounds (VOCs) during heterogeneous PCO reactions. To this end, two strategies have been widely investigated: one is to incorporate metal ion dopants and other semiconductor oxides (e.g., $\mathrm{ZrO}_{2}$ ) into $\mathrm{TiO}_{2}{ }^{4-7}$ the other is to develop sorbent- $\mathrm{TiO}_{2}$ hybrid photocatalysts. ${ }^{6-8}$ Although the catalyst derived from both strategies has significantly higher activities than the pure $\mathrm{TiO}_{2}$, it is not known which strategy is more advantageous because no direct comparison (against the same reactant in the same reactor) has ever been made. However, sorbent- $\mathrm{TiO}_{2}$ hybrids such as adsorption enhanced $\mathrm{TiO}_{2}-\mathrm{SiO}_{2}$ catalyst and the Silica-Titania Composite (STC) from Sol-gel Solutions, LLC demand special attention because of the high adsorption capacity of its porous silica that not only concentrates organic contaminants near the catalyst site, but also retains the oxidation intermediates. The adsorption enhanced $\mathrm{TiO}_{2}-\mathrm{SiO}_{2}$ catalyst was shown to perform significantly better than $\mathrm{TiO}_{2}$ alone even for toluene (a highly recalcitrant VOC) by achieving $70 \%$ removal from a continuous flow of $1 \mathrm{ppm}_{\mathrm{v}}$ toluene at a high face velocity of $176 \mathrm{ft} \mathrm{min}^{-1}$ (equivalent to $0.34 \mathrm{~s}$ contact in a 12 " path reactor). ${ }^{9}$

The STC was engineered as a post-processor technology for water recovery by the Environmental Systems Commercial Space Technology Center (ES-CSTC) at the University of Florida and commercialized under Sol-Gel Solutions, LLC. It has been evaluated for applications in mercury removal and pathogen deactivation, and has also been tested at the bench and/or pilot scale for the removal of volatile organic contaminants (VOCs) from gases emitted from pulp and paper mills and from indoor air. ${ }^{10-13}$ A steady state methanol removal from a continuous flow of $95 \% \mathrm{RH}$ air stream was reported to be $48 \%, 62 \%$, and $97 \%$ at the space time $(\tau)$ of $1.1 \mathrm{~s}, 2.1 \mathrm{~s}$, and $8.6 \mathrm{~s}$, respectively. ${ }^{12}$ However promising, the formaldehyde formation and its subsequent release was not eliminated. Formaldehyde was found in the effluent at the level of 8,3 , and $0.3 \mathrm{ppm}_{\mathrm{v}}$ for the corresponding contact times tested. Furthermore, the STC was only tested with methanol, toluene, and ethanol individually at two extreme relative humidity levels $(12 \%$ and $95 \%)$; further tests under more realistic conditions associated with the proposed application (e.g., other RH levels and shorter contact time) are needed. Because of the STC's enhanced adsorptive capacity for VOCs, it has been suggested that STC-catalyzed PCO may be operated in alternating dark and 
illuminated cycles to reduce the overall power consumption. The low power dark cycle will effectively load the STC with VOCs that will subsequently be oxidized during a period of UV illumination (i.e., batch PCO or transient PCO). The question is posed: Is batch PCO as effective as continuous PCO?

A previous study of STC-catalyzed mineralization of methanol showed that mineralization efficiency was greater with UV-C $\left(\lambda_{\max }=254 \mathrm{~nm}\right)$ compared to UV-A $\left(\lambda_{\max }=365 \mathrm{~nm}\right)$ light, but the UV-C lamp also turned out to have a higher UV output than the UV-A lamp. ${ }^{11}$ Therefore, it is not known whether the positive effect of the UV-C on PCO is due to its higher light intensity or its higher photonic efficiency. This question is of critical importance in designing an energy-efficient and low-risk PCO reactor because a) UV-C radiation is more damaging than UV-A in spite of the fact that current UV-C lamps have a higher electrical efficiency over that of UV-A lamps and b) the electrical efficiency and life expectancy of UV Light Emitting Diode (LED) devices (one of the non-mercury alternative UV sources) increases with the shift to longer wavelengths. ${ }^{14}$ Using ethanol as a representative polar VOC, this study aimed to address four specific questions: 1) is UV-C a more effective and efficient photon source for STC-catalyzed PCO than UV-A provided both have the same photon flux? 2) how does the relative humidity of a typical crew cabin (approximately $45 \% \mathrm{RH}$ ) affect the PCO efficiency and intermediate formation? 3) is batch PCO feasible? and 4) can the STC sustain its photocatalytic activity over time?

\section{Materials and Method}

\section{A. Light Sources and Irradiance Measurement}

An 8-W UV-A (F8T5) linear fluorescent lamp (UV-A FL) from Phillips and an 8-W UV-C (G8T5/OF) germicidal lamp (UV-C GL) from Sylvania of the same dimension were used as the light sources. The irradiance of each light source was measured outside a quartz sleeve $(28 \mathrm{~mm}$ OD) that envelops the UV light source to simulate the irradiance at the surface of the catalyst. Measurements were made when the light source was brand new (after a 24-hour burn in period) as well as after a regular interval of use to ensure a constant irradiance was used among different tests. The measurement was conducted in a dark room using an OL754C spectroradiometer fitted with a integrating sphere (Optronics Laboratories, Orlando, FL). Two additional levels of UV-C irradiance were achieved by wrapping the UV-C lamp with one or two layers of metal mesh screen and similarly determined to enable the investigation of the effect of UV irradiance on photocatalysis. The irradiance values were used to calculate the incident photon flux.

\section{B. Photocatalyst Specification}

STC pellets from Sol-gel Solutions, LLC (Gainesville, FL) with dimensions of $1.5 \pm 0.1 \mathrm{~mm}(w) \times 6.1 \pm 0.1 \mathrm{~mm}$ (L) were used. The STC had the same specifications as that used in a previous study. ${ }^{11}$ It contains $4 \% \mathrm{TiO}_{2}(4 \mathrm{~g}$ Degussa P-25 in $100 \mathrm{~mL}$ silica precursor, tetraethyl orthosilicate), has a pore size of approximately $30-40 \AA$, pore volume of $0.79 \mathrm{~mL} \mathrm{~g}^{-1}$, and a BET surface area of $616 \mathrm{~m}^{2} \mathrm{~g}^{-1}$.

\section{PCO tests}

The STC's performance was evaluated in a custom made quartz annular reactor (Southern Scientific, Inc. FL) as shown in Fig. 1. The reactor has an annular space of $5 \mathrm{~mm}$ for holding the catalyst and a water jacket for temperature control. The quartz sleeve that envelops the UV-source has an internal and external diameter of $25 \mathrm{~mm}$ and $28.8 \mathrm{~mm}$, respectively. The reactor was packed with $14.6 \mathrm{~g} \mathrm{STC}$ (dried in a muffle furnace at $180^{\circ} \mathrm{C}$ for $2 \mathrm{~h}$ and equilibrated to room temperature in a dessicator), resulting in a path length of $65 \mathrm{~mm}$ (i.e packing density is $0.43 \mathrm{~g}$

$\mathrm{cm}^{-3}$ ). The same batch of STC catalyst was repeatedly used for all the tests reported in this paper; it was re-generated between tests in-line at room temperature with a UV source on while sweeping with VOC-free humidified air. Completion of the regeneration was indicated by no detectable amount of VOCs by GC analysis and only baselinelevel $\mathrm{CO}_{2}$ in the effluent.

Experiments were carried out in a PCO testbed described in a previous paper. ${ }^{15}$ The testbed has the capability to control experiment variables (VOC concentration, $\mathrm{RH}$, flow rate, temperature) and continuously monitor the PCO reaction. It consists of three subsystems: 1 ) a simulated contaminated air generation system for supplying the desired concentration of VOCs and desired RH air; 2) a PCO reactor with active temperature control; and 3) a monitoring and analysis system made of mass flow controllers, thermocouples, humidity and pressure sensors, a $\mathrm{CO}_{2}$ analyzer, and a gas chromatograph equipped with a flame ionization detector (GC/FID). The PCO reactor influent and effluent 
were sampled alternately via a sample-stream selecting valve every $8.45 \mathrm{~min}$ and analyzed for ethanol and any oxidation intermediates by $\mathrm{GC} / \mathrm{FID}$. The effluent was also directed to a $\mathrm{CO}_{2}$ analyzer to determine the production of $\mathrm{CO}_{2}$, the complete mineralization product. $\mathrm{CO}_{2}$ concentration was recorded every minute. Influent flow rate, contaminant (ethanol) concentration, and PCO reactor temperature were maintained constant at $2 \mathrm{~L} \mathrm{~min}^{-1}$ humid air $\left(21 \% \mathrm{O}_{2}, 79 \% \mathrm{~N}_{2}, 0 \mathrm{ppm} \mathrm{CO}_{2}\right), 55.3 \pm 1.4 \mathrm{ppm}$, and $25 \pm 0.1{ }^{\circ} \mathrm{C}$, respectively. This gave rise to a face velocity of $6.28 \mathrm{~cm} \mathrm{~s}^{-1}$ or $1.03 \mathrm{~s}$ space time $(\tau)$ in the annular reactor of $5 \mathrm{~mm} \times 65 \mathrm{~mm}$ catalyst bed as well as an ethanol-loading rate of $0.21 \mathrm{mg} \mathrm{min}^{-1}$. In order to facilitate the comparison of test results among different laboratories, apparent contact time of VOCs with the catalyst in the reactor was calculated by multiplying $\tau$ with the catalyst volume fraction. The catalyst volume fraction was determined by fluid displacement to be $26 \%$ of the catalyst bed, consequently the apparent contact was $0.27 \mathrm{~s}$. Experimental variables are the light source (UVA vs. UV-C), photon flux, and relative humidity as shown in Table 1. Experiments were conducted in three modes: simultaneous PCO, dark adsorption/reaction, and transient or batch PCO.

Simultaneous PCO: This was an open-loop single pass mode where a $2 \mathrm{~L} \min ^{-1}$ simulated contaminant air flowed through the PCO reactor continuously with the UV source on. In a typical test, the following routine was followed: First, a VOC-free gas stream with desired relative humidity (RH) flowed through the reactor to condition the STC pellets to a predetermined test RH under continuous illumination. After the

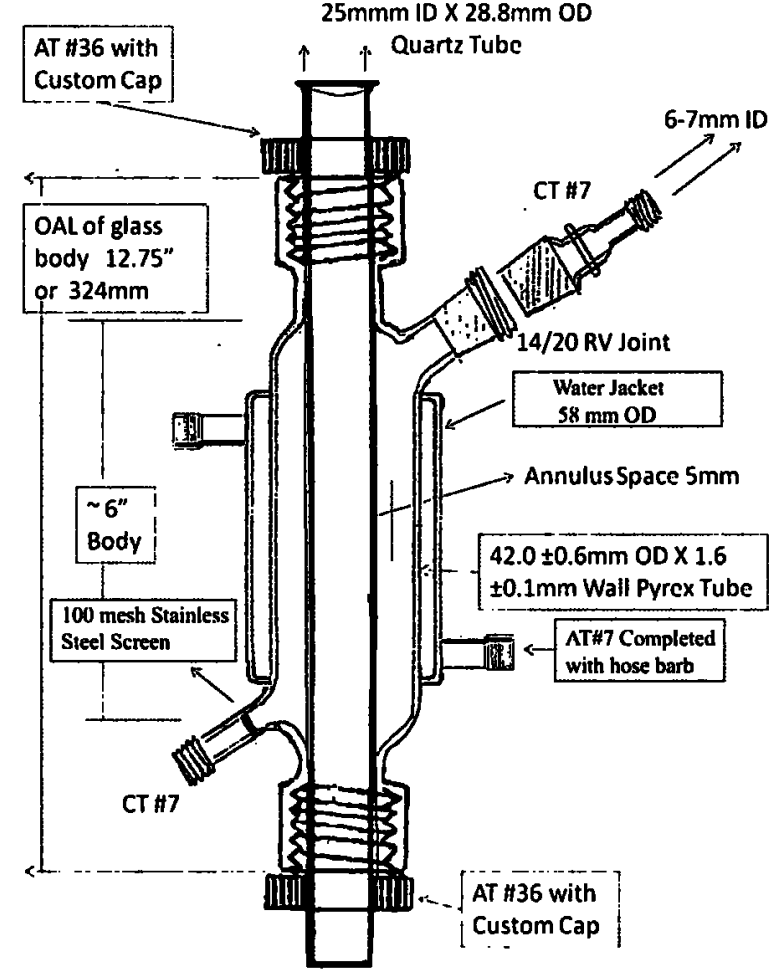

Figure 1. Annular reactor with a water jacket.

Table 1. Summary of Experimental Variables

\begin{tabular}{lcccc}
\hline PCO Mode & UV Source & $\begin{array}{c}\text { Irradiance } \\
\left(\mathrm{mW} \mathrm{cm}^{-2}\right)^{*}\end{array}$ & $\begin{array}{c}\text { Photon Flux } \\
(\mu \mathrm{mol} \mathrm{s})^{* *}\end{array}$ & RH\% at 23 ${ }^{\circ} \mathrm{C}$ \\
\hline Simultaneous PCO & UV-C GL & 2.71 & 0.34 & 75 \\
Simultaneous PCO & UV-C GL & 5.17 & 0.64 & 75 \\
Simultaneous PCO & UV-C GL & 7.18 & 0.89 & 75 \\
Simultaneous PCO & UV-A FL & 3.44 & 0.63 & 17 \\
Simultaneous PCO & UV-A FL & 3.44 & 0.63 & 45 \\
Simultaneous PCO & UV-A FL & 3.44 & 0.63 & 75 \\
Ethanol Adsorption & None & 0.0 & 0.0 & 17 \\
Ethanol Adsorption & None & 0.0 & 0.0 & 45 \\
Ethanol Adsorption & None & 0.0 & 0.0 & 75 \\
Transient PCO & UV-A FL & 3.44 & 0.63 & 17 \\
Transient PCO & UV-A FL & 3.44 & 0.63 & 45 \\
Transient PCO & UV-A FL & 3.44 & 0.63 & 75 \\
\hline "Irradiance at the outside of a quartze sleeve that envelops the UV light source, maintained within $\pm 3 \%$. \\
**Calculated from the irradiance value on the basis of the external surface area of a 28 mm OD quartze sleeve that \\
STC pellets covered.
\end{tabular}


reactor inlet and outlet humidity levels reach equilibrium, the contaminant was then introduced. The test pollutant was simultaneously adsorbed and oxidized. Ideally, a steady state is established when the outlet pollutant concentration no longer changes. However, the time to reach the steady state varies depending upon many factors; the true steady state was not reached within the duration of the experiment $(>21 \mathrm{~h})$. Instead, a pseudo-steady state was defined when $\mathrm{CO}_{2}$ formation reached a constant rate. It was at this state that the concentration of effluent VOCs and $\mathrm{CO}_{2}$ were used to calculate the ethanol removal and mineralization. Each simultaneous PCO test was followed by regeneration using humid VOC-free air and continuous illumination as shown in Fig. 2.

Dark adsorption/reaction: During this type of experiment, the light was not turned on when the contaminant was introduced. These experiments not only allowed for the assessment of whether there were any STC-catalyzed reactions without light, but also provided a qualitative indication of the adsorption capacity between the STC catalyst and the pollutant. After the adsorption process reached equilibrium as indicated by equality between the inlet and outlet pollutant concentrations, PCO was initiated by turning on the UV source along with a stream of VOC-free humid air. This alos served as in-line regeneration of the catalyst as well.

Batch or Transient PCO: A single contaminant (ethanol in this case) was adsorbed onto the catalyst to saturation at room temperature with the UV light off and PCO was initiated by turning the UV light on. The regeneration phase post-dark adsorption is an example of transient PCO.

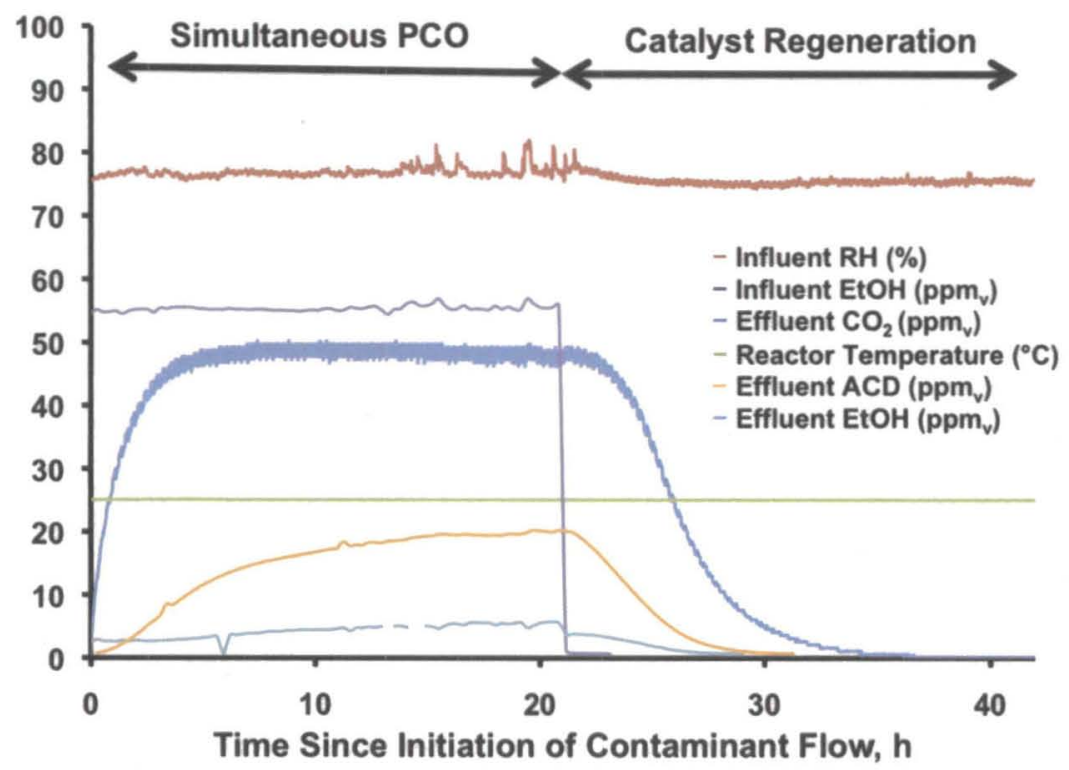

Figure 2. An example of a typical simultaneous PCO experiment and the key paremeteres collected.

\section{Data Analysis}

PCO performance under a specific condition was quantified by the EtOH removal and mineralization efficiency $\left(\mathrm{X}_{\mathrm{A}}\right)$ at a given time point or the steady state. EtOH removal is the measure of the removal of influent ethanol regardless of it being adsorbed or oxidized, whereas mineralization efficiency is the measure of complete oxidation of EtOH to $\mathrm{CO}_{2}$. They were calculated using equations (1) and (2), respectively. Where $[\mathrm{EtOH}]_{\text {in }}$ and $[\mathrm{EtOH}]_{\text {out }}$ are the influent and effluent ethanol concentrations, $[\mathrm{EtOH}]_{\text {out }} /[\mathrm{EtOH}]_{\text {in }} \mathrm{x} 100$ is the percentage of effluent ethanol normalized to its influent concentration. $\left[\mathrm{CO}_{2}\right]_{\text {out }}\left[\mathrm{CO}_{2}\right]_{\text {in }}$ is the net $\mathrm{CO}_{2}$ generated by the PCO. Therefore, mineralization efficiency is also the percentage of net $\mathrm{CO}_{2}$ normalized to the influent carbon. 
The kinetics for $\mathrm{PCO}$ of ethanol was modeled on the formation of $\mathrm{CO}_{2}$ (product) rather than the disappearance of ethanol (reactant) because there is little adsorption of $\mathrm{CO}_{2}$ by STC. Cumulative $\mathrm{CO}_{2}$ concentration was plotted against the irradiation time, a least square fit was performed. The photonic efficiency $(\xi)$ was calculated as the ratio of the PCO rate to the incident photon flux by equation (3). Photonic effiency represents moles of $\mathrm{CO}_{2}$ formation per mole of photons, hence it is used interchagibly with reaction quantum yield in the text.

$$
\begin{aligned}
& \text { EtOH Removal }(\%)=\frac{([E t O H] \text { in }-[E t O H] \text { out })}{[E t O H] \text { in }} \times 100=\left(1-\frac{[E t O H] \text { out }}{[E t O H] \text { in }}\right) \times 100 \\
& X_{\mathrm{A}}=\frac{\left(\left[\mathrm{CO}_{2}\right] \text { out }-\left[\mathrm{CO}_{2}\right] \text { in }\right)}{2 \times[E t O H] \text { in }} \times 100 \\
& \xi=\frac{\text { PCO rate }\left(\mathrm{mol} \mathrm{L}^{-1} \mathrm{~s}^{-1}\right)}{\text { incident photon flux }\left(\mathrm{mol} \mathrm{s}^{-1}\right)}
\end{aligned}
$$

\section{Results and Discussion}

\section{A. STC-catalyzed PCO efficiency under UV-C vs. UV-A at $75 \%$ RH and $25^{\circ} \mathrm{C}$ Effect of Photon Flux of the UV-C light source on STC-Catalyzed Oxidation of Ethanol}

Figures 3a through $3 \mathrm{c}$ show the change in normalized effluent composition over time after the onset of contaminant flow and UV illumination. Regardless of the light source (UV-A or UV-C) or irradiance, there were three components detected in the effluent stream: ethanol, $\mathrm{CO}_{2}$, and acetaldehyde (ACD). Both the evolution rate of effluent components and the concentration of effluent components at any given time were profoundly affected by the irradiance at the catalyst surface. Although $\mathrm{CO}_{2}$ production, hence mineralization, reached a steady state after about $5 \mathrm{~h}$, the effluent ethanol and ACD concentration continued to increase during the $21 \mathrm{~h}$ of the experiment with continuous input of ethanol at a rate of $0.21 \mathrm{mg} \mathrm{min}^{-1}$. The increase of irradiance or photon flux of UV-C from 38 , to 72 to $100 \%$ reduced the rate of ethanol and ACD evolution (Fig. 3a and 3b) while it increased the rate of $\mathrm{CO}_{2}$ production (Fig. 3c). The rate of $\mathrm{CO}_{2}$ evolution was used to estimate the overall $\mathrm{PCO}$ rate. The dependence of the PCO rate on photon flux of the UV-C was a half order (Fig. 3f), in agreement with previous findings that $r=\mathrm{KI}^{0.5}$ when the "I" exceeds $2 \mathrm{~mW} \mathrm{~cm}{ }^{-2}{ }^{7,16}$ In other words, STC-catalyzed PCO rate is approximately the square root of the incident radiation within the irradiance range $\left(2.71-7.2 \mathrm{~mW} \mathrm{~cm}^{-2}\right)$ tested in this study. At the mean time, the photonic efficiency or reaction quantum yield decreased as the photon flux increased $\left(\xi=49.243 q_{n, p}{ }^{-0.51}\right.$ $\left.R^{2}=0.992\right)$. In other words, energy-use efficiency decreases at a significantly large photon flux although it also leads to increased mineralization and reduced intermediate accumulation (Fig. 3c and 3e). A balance between energy-use efficiency and PCO efficiency must be achieved when designing a PCO reactor. A comparison between UV-A and UV-C light at the same photon flux revealed that the UV-A irradiated catalyst showed a higher acetaldehyde evolution rate (Fig. 3e), and a lower PCO rate than in the UV-C irradiated experiment (32.4 vs. 39.3 nmol L $\mathrm{s}^{-1}$ ), though there was no significant difference in the ethanol removal (Fig. 3d). Consequently, the reaction quantum yield of the UV-C photons is greater (1.2 times) than that of UV-A photons. 



Figure 3. Effect of light source on the simultaneous PCO of ethanol in an STC-packed annular reactor at $75 \%$ RH: time courses of normalized effluent a) ethanol, b) acetaldehyde, and c) $\mathrm{CO}_{2}$, and relationships d) between photon flux and ethanol removal, e) between photon flux and acetaldehyde evolution rate, and f) photon flux and PCO rate. 
Intermediates formed during simultaneous PCO of ethanol on STC pellets

Gas chromatographic analyses of the PCO effluent under all conditions examined in this study showed that there was no detectable amount of other organics other than acetaldehyde and ethanol. Carbon dioxide was the final oxidation product. Although the PCO of ethanol on the $\mathrm{TiO}_{2}$ surface is known to follow two parallel pathways: ${ }^{17}$ 1) Ethanol $\rightarrow$ acetaldehyde $\rightarrow$ acetic acid $\rightarrow \mathrm{CO}_{2}+$ formaldehyde $\rightarrow$ formic acid $\rightarrow$ $\mathrm{CO}_{2}$ and 2) Ethanol $\rightarrow$ acetaldehyde $\rightarrow$ formic acid+formaldehyde $\rightarrow$ formic acid $\rightarrow \mathrm{CO}_{2}$; acetic acid, formic acid, and formaldehyde were not detected in our study. This suggests that they were oxidized at the same or faster rate that they were formed. Neither $\mathrm{CO}_{2}$ nor acetaldehyde were found in the dark adsorption studies, confirming that the STC does not catalyze the oxidation of ethanol in the absence of light. Furthermore, the carbon mass balances for all the tests at $75 \% \mathrm{RH}$ were within $\pm 6 \%$ (Fig. 4) of the total ethanol carbon introduced to the system. Although carbon monoxide was not monitored, it would be negligible if there were any because its formation is often associated with photolysis (i.e. photodissociation in the absence of a photocatalyst) and usually occurs under higher light intensity (e.g. $>25 \mathrm{~mW} \mathrm{~cm}^{-2}$ ) than those

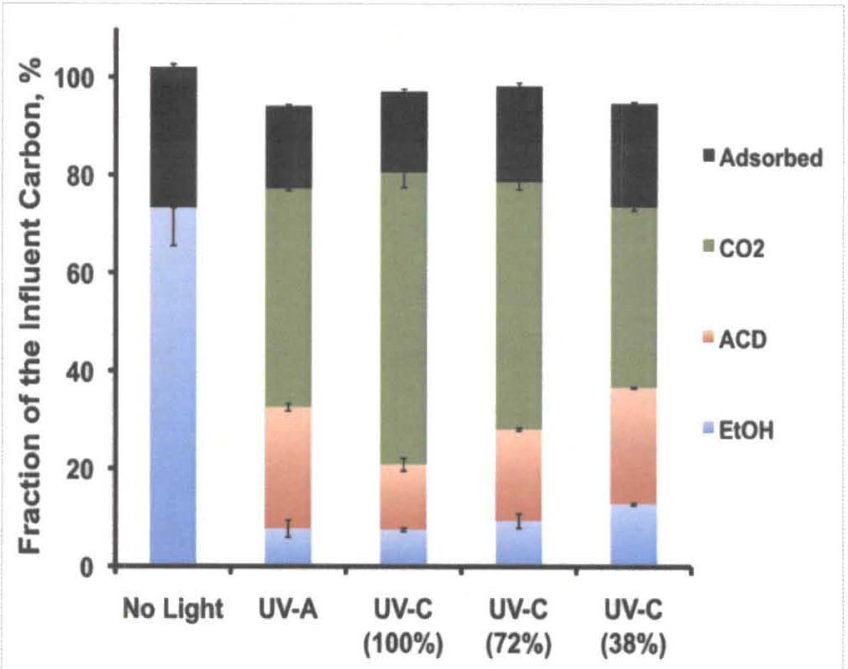

Figure 4. Carbon balance during the simultaneous PCO of ethanol in a STC-packed annular reactor operated at $25^{\circ} \mathrm{C}$ and $75 \% \mathrm{RH}$ representing the average and standard deviation of at least two replicates for each treatment. Adsorbed carbon was obtained by analyzing the effluent during catalyst regeneration as described in "Materials and Method." used in photocatalysis. ${ }^{18}$

\section{B. Effect of RH on ethanol adsorption and oxidation}

Ethanol adsorption

Regardless of the $\mathrm{RH}$, there was a S shape ethanol breakthrough curve that consisted of three phases: the initial lag, exponential increase, and steady state. Increasing the RH of the air stream resulted in a lower initial effluent ethanol concentration, a shorter lag time before the rapid increase of effluent ethanol concentration, and a steeper slope of the adsorption breakthrough curve (Fig. 5a). In other words, the higher the RH is, the faster ethanol reaches
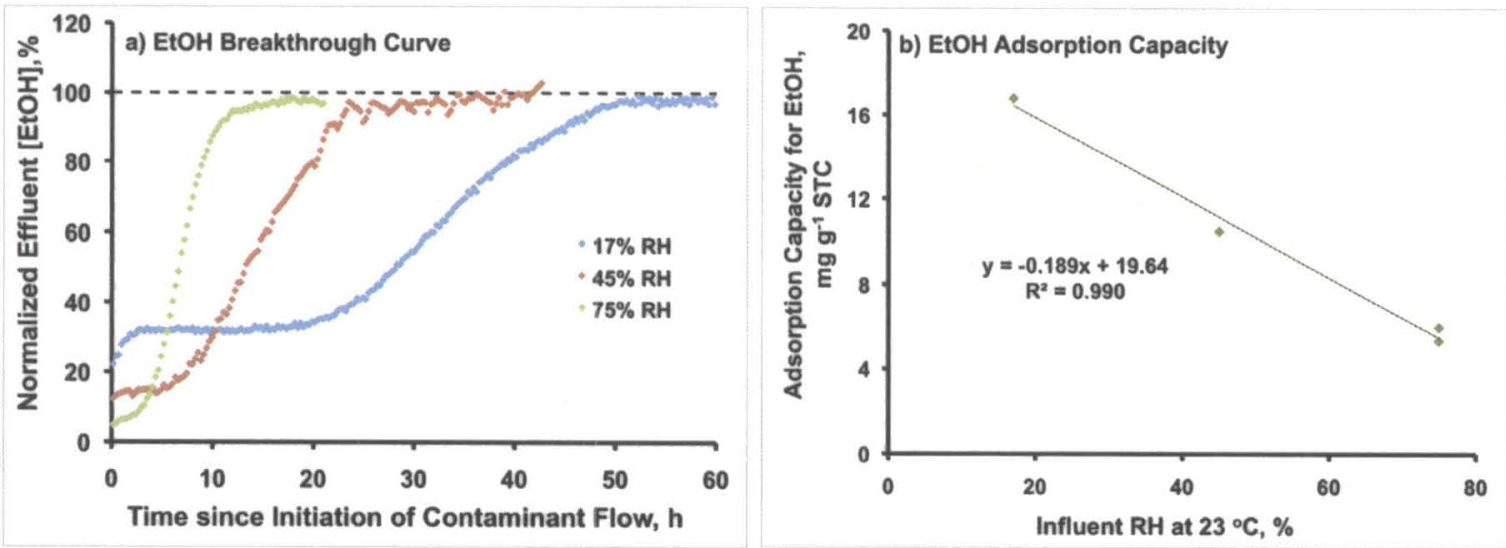

Figure 5. Effect of relative humidity in the air stream on the adsorption of ethanol by the STC: a) time course of normalized effluent ethanol concentration and b) ethanol adsorption capacity. 
its breakthrough point. The time for $95 \%$ breakthrough to occur for 17,45 , and $75 \% \mathrm{RH}$ was $48.0,23.5$ and $12.0 \mathrm{~h}$, respectively.

There was a negative correlation between adsorption capacity for ethanol and RH (Fig. 5b), suggesting a competitive nature of water and ethanol adsorption by the silica component of the STC. If the linear regression were to be employed to predict the adsorption capacity for ethanol at $12 \%$ and $95 \% \mathrm{RH}$, it would be 17.4 and $1.7 \mathrm{mg}$ ethanol $\mathrm{g}^{-1}$ STC (or 0.3777 and $0.0377 \mathrm{mmol}$ ethanol $\mathrm{g}^{-1} \mathrm{STC}$ ) respectively. These adsorption capacities are translated into 12.08 and $1.17 \mathrm{mg}$ methanol equivalent $\mathrm{g}^{-1}$ STC, consistent with previous findings (11.0 and $1.2 \mathrm{mg}$ methanol g-1 STC for RH $12 \%$ and RH 95\%, respectively) in Mazyck's lab. ${ }^{11}$

Although there was a greater adsorption capacity for ethanol at the low $\mathrm{RH}$, it is intriguing to find that the initial effluent ethanol concentration at the low RH was higher relative to that at the high RH. This result implies that a small amount of adsorbed water facilitates the adsorption of ethanol on STC and consequently the removal of ethanol from air.

\section{Simultaneous PCO}
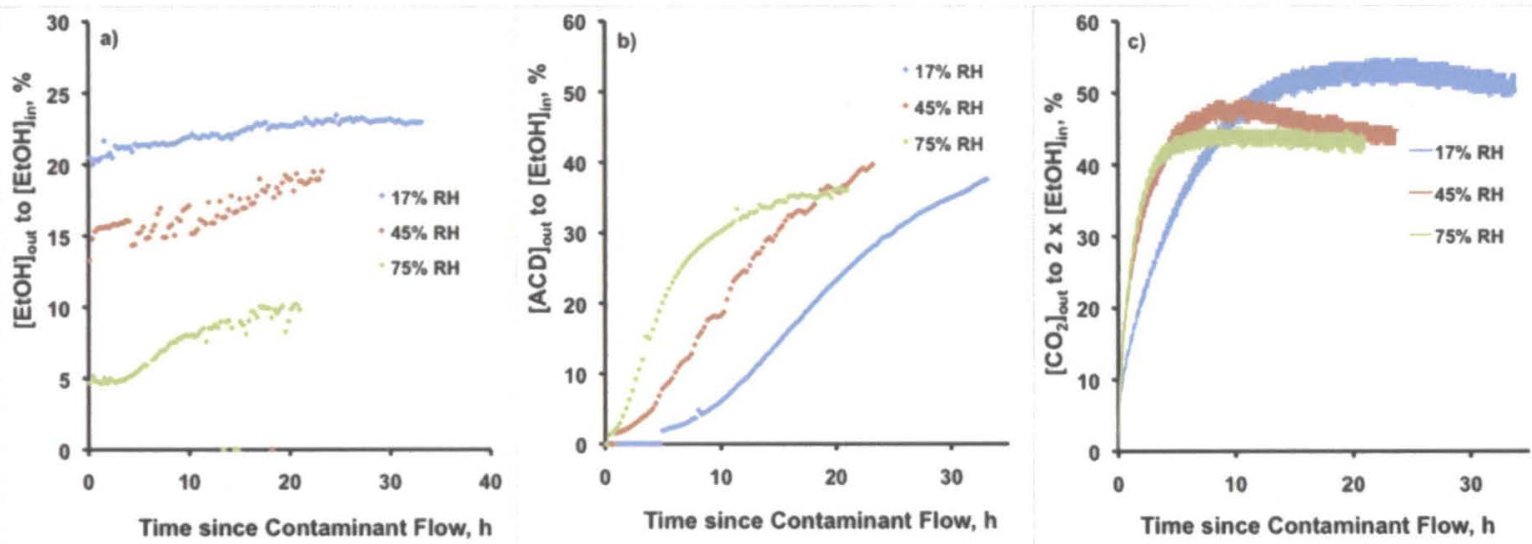

Figure 6. Effect of influent RH on the simultaneous PCO of ethanol under continuous irradiation of UV-A FL: a) effluent ethanol profile, b) effluent acetaldehyde profile, and c) effluent carbon dioxide profile.

The effect of RH on the simultaneous PCO was not only reflected in effluent ethanol concentration, but also in its oxidation intermediate (acetaldehyde) as well as the PCO rate (Fig. 6) The effluent ethanol concentration (Fig. 6a) during the simultaneous PCO followed the same trend as that during ethanol adsorption, being the highest at $17 \% \mathrm{RH}$, then $45 \% \mathrm{RH}$, and finally $75 \% \mathrm{RH}$. However, there was not a rapid increase phase due to the continuous oxidation of the adsorbed ethanol. The RH had an opposite effect on effluent acetaldehyde concentration (Fig. 6b). Effluent acetaldehyde concentration was much lower at $17 \%$ RH than at $45 \%$ and $75 \%$ for a substantial time period of the experiment; the rate of acetaldehyde evolution was also lower at $17 \% \mathrm{RH}$ compared to at $45 \%$ and $75 \% \mathrm{RH}$. This result can be explained by the fact that there are more sites within the STC that are available for adsorption and subsequent oxidation of acetaldehyde at the low RH than there are at the high RH. However, as the experiment progresses, more water molecules than ethanol or acetaldehyde are being selectively adsorbed onto the STC surface in the low RH than in the high RH air streams (i.e., there is a higher selectivity ratio of water to ethanol and/or acetaldehyde for adsorption at $17 \%$ than $45 \%$, and $45 \%$ than $75 \% \mathrm{RH}$ ), and a crossover point is eventually reached. This trend shows that the effluent acetaldehyde concentration after this point is in a decreasing order from $17 \% \mathrm{RH}$ to $45 \% \mathrm{RH}$ to $75 \% \mathrm{RH}$. The mineralization efficiency, $\mathrm{X}_{\mathrm{A}}$ (Fig. 5c), generally followed the acetaldehyde trend, but the difference among RH levels was smaller. Nevertheless, at $20 \mathrm{~h}$, the $17 \% \mathrm{RH}$ air stream had the highest mineralization, the lowest effluent acetaldehyde, and, interestingly, the lowest ethanol removal; there was no significant difference in these attributes between the $45 \%$ and $75 \% \mathrm{RH}$ experiments. The observation of high mineralization with concomitant low ethanol removal at the low RH seems contradicting. The same series of experiments were repeated under UV-A LED irradiation, resulting in similar trends (data not shown); validating the finding. The enhancement of mineralization by reduced $\mathrm{RH}$ may be the result of accelerated oxidation of acetaldehyde rather than of the oxidation of ethanol, whereas reduced ethanol removal in low RH is primarily due to 
the reduced adsorption rate of ethanol by the STC (note that the high adsorption capacity does not necessarily mean a high adsorption rate). Plotting the cumulative $\mathrm{CO}_{2}$ concentration against UV irradiation time showed that the PCO of ethanol fits a zero order kinetic trend $\left(\delta\left[\mathrm{CO}_{2}\right] / \delta \mathrm{t}=\mathrm{k}\right.$ ) regardless of the $\mathrm{RH}(\mathrm{Fig} .7 \mathrm{a}) . \mathrm{CO}_{2}$ production was initially at a slower rate in $17 \%$ than those in $45 \%$ and $75 \% \mathrm{RH}$. However, as the experiment progressed, the overall PCO rate increased and became higher in the $17 \% \mathrm{RH}$ air than those in the other two RH levels examined (Fig. 7a and Table 2). In the mean time, the acetaldehyde evolution rate was the lowest at $17 \% \mathrm{RH}$ and increased as the $\mathrm{RH}$ increased (Table 2). Taking all these results into consideration, low RH benefits the mineralization and reduces intermediate evolution. These results are in agreement with previous findings on PCO of methanol under UV-C, which demonstrated that increasing $\mathrm{RH}$ from 12 to $95 \%$ decreased $\mathrm{MeOH}$ adsorption capacity and $\mathrm{PCO}$ efficiency with concomitant increase in effluent formaldehyde. ${ }^{11}$

Transient PCO vs. simultaneous PCO

A direct comparison between simultaneous PCO and batch PCO showed that they have very different PCO kinetics. The former more or less sustained the same rate of $\mathrm{CO}_{2}$ production for each $\mathrm{RH}$ stream throughout the experiment (Fig. 7a), whereas $\mathrm{CO}_{2}$ production rate in the batch $\mathrm{PCO}$ dramatically decreased at the later time of the experiment when there was still a large amount of ethanol (approximately $12 \%$ of the total ethanol adsorbed at each respective $\mathrm{RH}$ ) remained on the STC bed (Fig. 7b). This decrease in PCO rate is due to the decline of VOC molecules (whether being ethanol or its oxidation intermediates) at the STC surface directly exposed to the UV light. It was also found that PCO rate in transient PCO mode was also higher at $17 \%$ RH than at either $45 \%$ or $75 \%$ $\mathrm{RH}$ (Table 2), in agreement with the result from simultaneous PCO. Above all, at any given RH level, the PCO rate in the transient PCO mode was significantly lower, whereas the intermediate ACD evolution rate was significantly higher compared with those in the simultaneous PCO mode. This finding cautions the use of a batch PCO reactor in a closed environment because of the potential evolution of a large amount ( 2 to 4 times the value found in simultaneous $\mathrm{PCO}$ ) of more toxic intermediates.
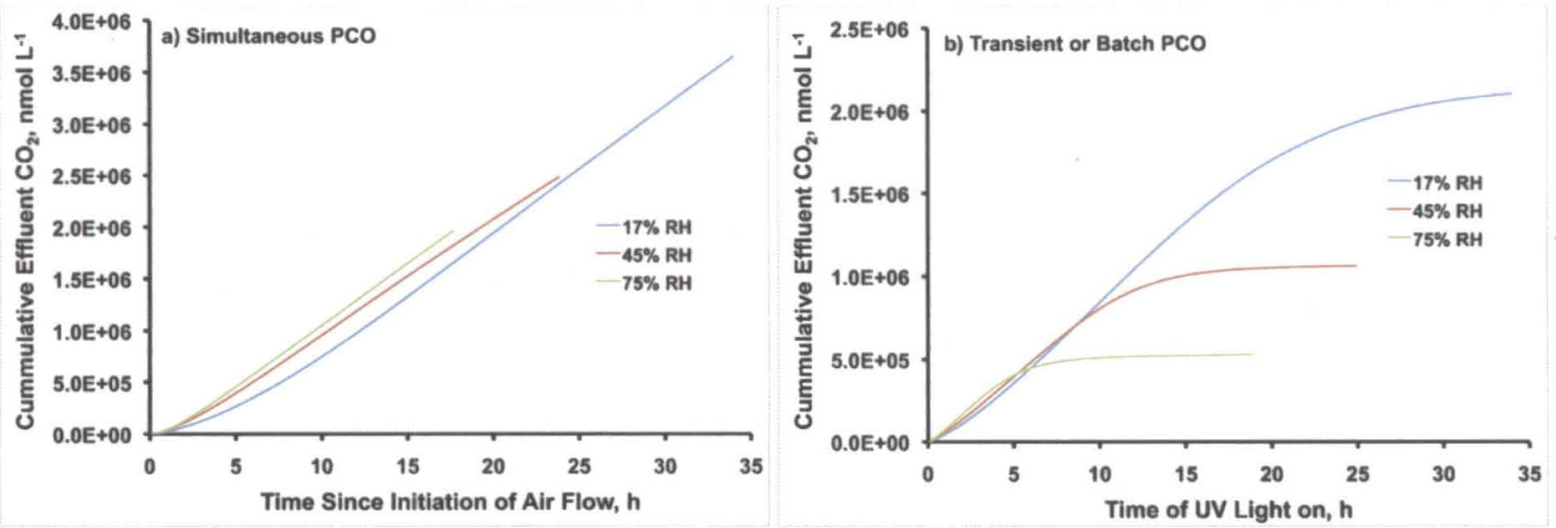

Figure 7. Rate of carbon dioxide $\left(\mathrm{CO}_{2}\right)$ formation during simultaneous and transient PCO processes.

Table 2. Rate of $\mathrm{CO}_{2}$ formation (or overall PCO rate) and of Acetaldehyde Evolution (nmol $\mathrm{L}^{-1} \mathrm{~s}^{-1}$ ) during Simultaneous and Transient PCO

\begin{tabular}{ccccc}
\hline & \multicolumn{2}{c}{ Simultaneous PCO } & \multicolumn{2}{c}{ Transient PCO } \\
\hline $\mathrm{RH}_{\mathrm{i}}(\%)$ & $\mathrm{CO}_{2}$ Rate & $\mathrm{ACD}$ Rate & $\mathrm{CO}_{2}$ Rate & ACD Rate \\
17 & 35.62 & 0.61 & 25.80 & 2.48 \\
45 & 31.00 & 0.69 & 23.38 & 1.69 \\
75 & 31.94 & 0.75 & 24.56 & 1.67 \\
\hline
\end{tabular}




\section{Stability of STC activity}

During simulatenous $\mathrm{PCO}$, it was noted that the so-called pseudo-steady state $\mathrm{CO}_{2}$ concentration was not really constant and had a trend to drift downward slightly in UV-A illuminated reactor, but not in UV-C reactor (Fig. 3c and Fig. 6c). The small decline in $\mathrm{CO}_{2}$ production may be due to the accumulation of acetaldehyde on the catalyst surface that is known to decrease the reactivity of other intermediates. ${ }^{17}$ Although there is a potential for the decline of the STC's photocatalytic activity overtime, it can be prevented if a periodic complete regeneration of STC is performed. The combination of a humid air stream and UV illumination proved to be more effective in the catalyst regeneration than by either a sweeping gas flow or UV illumination alone. Regenerability and stability of the catalyst performance were demonstrated by very little change in ethanol removal, mineralization efficiency, and PCO rate over the 17 cycles (i.e., about 2 months of continuous operation in three different modes) (Fig. 8).

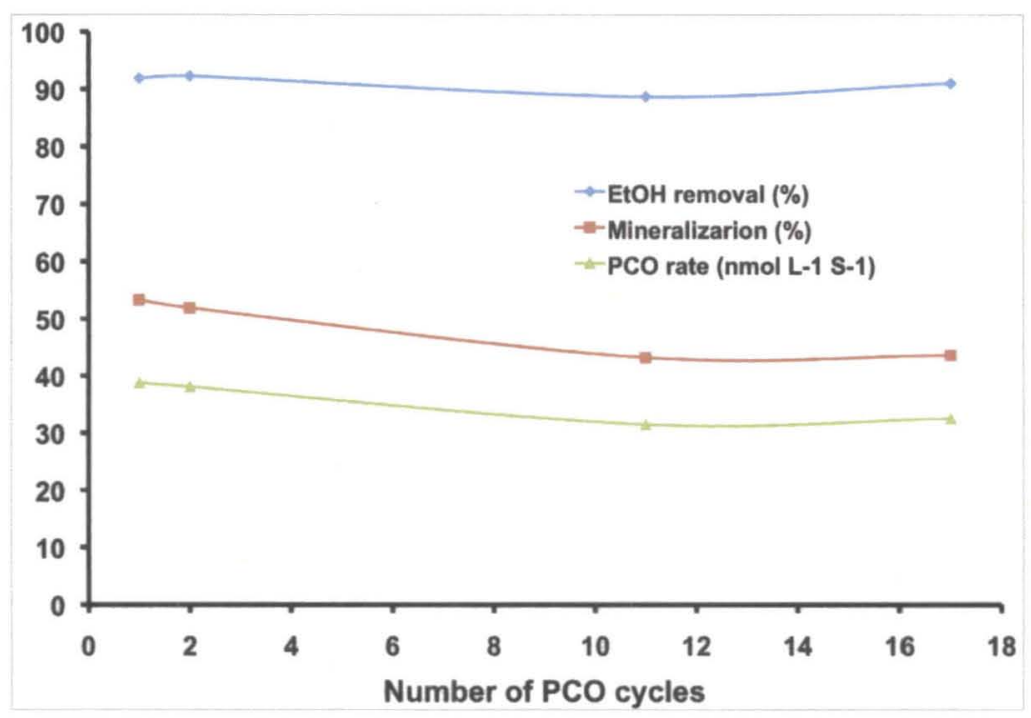

Figure 8. Repeatibility of the STC's performance in the removal of ethanol from an ethanol-contaminated $75 \% \mathrm{RH}$ air stream under UV-A irradiance after the STC had been subjected to repeated continuous PCO/in-line regeneration and dark adsorption/in-line regeneration cycles.

\section{Conclusion}

This study provided some valuable insights into the STC performance for photocatalytic removal of polar volatile organic contaminants such as ethanol at various $\mathrm{RH}$ levels in two operation modes. It is clear that mineralization efficiency and intermediate accumulation are highly dependent on the type of UV source and its photon flux, as well as the reactor operation conditions and mode. The UV-C germicidal lamp was shown to be a more effective and efficient light source for PCO because of its high electric and photonic efficiencies as well as its capability to reduce acetaldehyde formation when the photon flux of both light sources is equal. The mineralization efficiency for ethanol and PCO reaction rate increased with the incident photon flux within the range $(0.3$ to 0.9 $\mu \mathrm{mol}$ photon $\mathrm{s}^{-1}$, or 2.7 to $7.2 \mathrm{~mW} \mathrm{~cm}^{-2}$ ) examined, but its photonic efficiency decreased. Therefore, not only the photon flux but also the wavelength of UV light source (photon energy) must be meticulously taken into consideration in the design of an efficient $\mathrm{PCO}$ reactor.

The results also led to the following conclusions: 1) the STC alone does not catalyze the oxidization of ethanol (i.e., no ethanol oxidation or intermediate formation in the dark); 2) acetaldehyde (an intermediate of ethanol oxidation) is ubiquitous in the effluent of ethanol PCO by STC in the presence of UV light (UV-C or UV-A), although no quantifiable amount of other intermediates was observed in the effluent; 3) acetaldehyde evolution may be effectively reduced by an increase in photon energy and photon flux of a UV source as well as lowering RH in 
the process air; 4) although the PCO of ethanol at a slightly elevated temperature (e.g., $50 \mathrm{CC}$ ) has not been tested, effluent acetaldehyde concentration may be also reduced as the temperature increases; 5) simultaneous PCO is a preferred mode of operation to batch PCO because it not only has a higher mineralization efficiency, but also has 24 times less acetaldehyde depending upon the RH of process air; 6) the STC used for the PCO of ethanol is $100 \%$ regenerable under UV illumination and its performance has not shown significant decline over 2 months of continuous use. Together with the previous findings by Dr. Mazyck's group, results from this study shed light on the critical roles of reactor design-pertinent parameters (thickness of the catalyst layer, light sources and intensity, and reactor path length which govern the space time at a given flow rate) as well as operation (e.g., RH and PCO mode) in PCO efficiency. Though it may be challenging to eliminate the intermediate formation, it may be reduced to an inconsequential level via the combination of an innovative reactor design and optimized operation.

\section{Acknowledgements}

Support of this research was provided by NASA's Exploration Life Support Program - Air Revitalization Element and NASA's ISS Research. Authors would also like to thank Mr. Jay Perry and Dr. Raymond Wheeler for their insightful discussion and strategic direction.

\section{References}

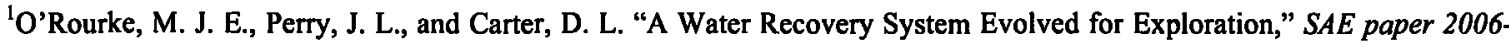
$01-2274,2006$

${ }^{2}$ Hodgson, A.T., Sullivan, D. P., and Fisk, W. J., "Evaluation of ultra-violet photocatalytic oxidation (UVPCO) for indoor air applications: Conversion of volatile organic compounds at low part-per-billion concentrations," $L B N L-58936,2005$.

${ }^{3}$ Deviliers, D., "Semiconductor photocatalysis: still an active research area despite barriers to commercialization," Energeia Vol. 17, No. 3, pp. 1-3, 2006.

${ }^{4} \mathrm{Fu}$, X., Clark, L.A., Yang, Q., and Anderson, M.A., "Enhanced photocatalytic performance of Titania-based binary metal oxides," Environ. Sci. Technol. Vol. 30, No. 2. Pp. 647-653, 1996.

${ }^{5}$ Zhao, J., and Yang, X. D., "Photocatalytical oxidation for indoor air purification: a literature review," Building and Environment, Vol. 38, pp. 645-654, 2003.

${ }^{6}$ Boul, P. J., "The Evaluation of Photocatalytic Oxidation and Thermal Catalytic Oxidation for a Trace Contaminant Control System," ESCG-4470-09-TEAN-DOC-0096, 2009.

${ }^{7}$ Mo, J., Zhang, Y., Xu, Q., Lamson, J. J., and Zhao, R., "Photocatalytic purification of volatile organic compounds in indoor air: a literature review," Atmospheric Environment Vol. 43, pp. 2229-2246, 2009.

${ }^{8}$ Yamaguchi, K., Inumaru, K., Oumi, Y., Sano, T., Yamanaka, S., "Photocatalytic decomposition of 2-propanol in air by mechanical mixtures of $\mathrm{TiO}_{2}$ crystalline particles and silicalite adsorbent: The complete conversion of organic molecules strongly adsorbed within zeolitic channels," Microporous and Mesoporous Materials, Vol.1 17, pp350-355, 2009.

${ }^{9}$ Zou, L., Luo, Y., Hooper, M., and Hu, E., "Removal of VOCs by photocatalysis processes using adsorption enhanced TiO2SiO2 catalyst," Chem. Eng. Process, Vol. 45, pp. 959, 2006.

${ }^{10}$ Stokke, J. M., Mazyck, D. W., Wu, C. Y., and Sheahan, R., "Photocatalytic oxidation of methanol using silica-titania composites in a packed-bed reactor," Environmental Prog. Vol. 25, No. 4, pp. 312-318, 2006.

${ }^{11}$ Stokke, J. M., and Mazyck, D. W., "Effect of catalyst support on the photocatalytic destruction of VOCs in a packed-bed reactor," SAE paper 2007-01-3138, 2007.

${ }^{12}$ Stokke, J. M., Mazyck, D. W., "Photocatalytic degradation of methanol using silica-titania pellets: Effect of pore size on mass transfer and reaction kinetics," Environmental Science \& Techology, Vol. 42, No. 10, pp. 3803-3813, 2008.

${ }^{13}$ Gruss, A.F., Casasus, A. I., and Mazyck, D. W., "VOC removal by novel regenerable silica-titania sorbent and photocatalytic technology," SAE paper 2009-01-2443, 2009.

${ }^{14}$ Sandhu, A., "The future of ultraviolet LEDs", Nature Photonics. Vol. 1, pp. 38, 2007.

${ }^{15}$ Levine, L.H., Richards, J.R., Soler, R.R., Maxik, F., Coutts, J., and Wheeler, R. W., "UV-LED as a light source for photocatalytic oxidation of trace organic contaminants," AIAA Paper \# 761667, 2010.

${ }^{16}$ Egerton, T. A. and King, C. J., "The influence of light intensity on photoactivity in TiO2 pigmented systems," Journal of the Oil and Colour Chemists' Association, "Vol. 62, pp386-391, 1979.

${ }^{17}$ Muggli,D. S., McCue, J. T., and Falconer, J. L., "Mechanism of the Photocatalytic Oxidation of Ethanol on TiO ${ }_{2}$," Journal of Catalysis, Vol. 173, pp 470-483, 1998. 
$D A A+k e<2011-125$

International Conference on Environmental Systems

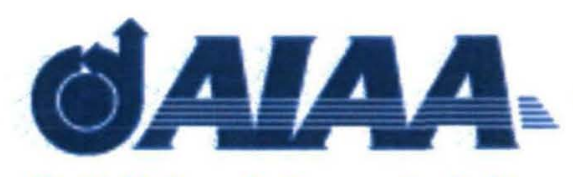

The Worlt's Fanum for Aerospoce leodership

\section{Silica-Titania Composite's Performance in Photocatalytic Oxidation of Polar VOCs}

Lanfang $\mathbf{H}$. Levine ${ }^{1}$, Janelle Coutts ${ }^{1}$, Jeffrey T. Richards ${ }^{1}$, and David Mazyck ${ }^{2}$ ${ }^{1}$ ESC-Team QNA, Kennedy Space Center, FL, 32899, USA

${ }^{2}$ Department of Environmental Engineering Sciences, University of Florida, Gainesville, FL 32611, USA

41th ICES, 17-21 July 2011,Portland, Oregon, USA 


\section{OAIAA :}

\section{BACKGROUND}

$\square$ Trace Contaminants and Polar Volatile Organic Compounds (VOC)

$\square$ Architecture of the ISS WRS or WPA and Proposed Application of Photocatalytic Oxidation (PCO) in WRS

$\square$ Silica-Titanium Composite (STC), an adsorption enhanced photocatalyst for PCO 


\section{Trace Contaminants in the ISS Atmosphere}

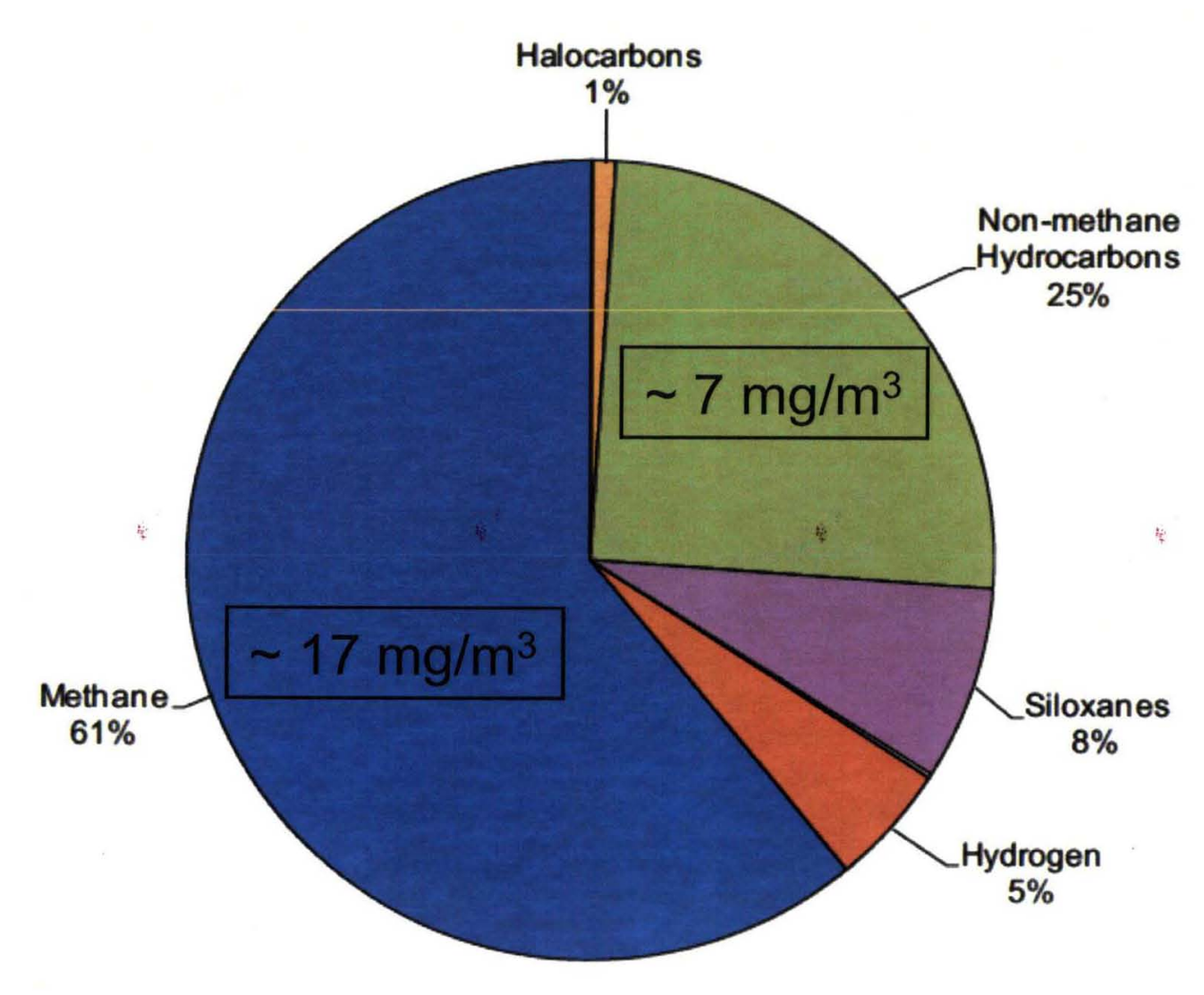

Jay Perry’s ICES paper \#2009-01-2592

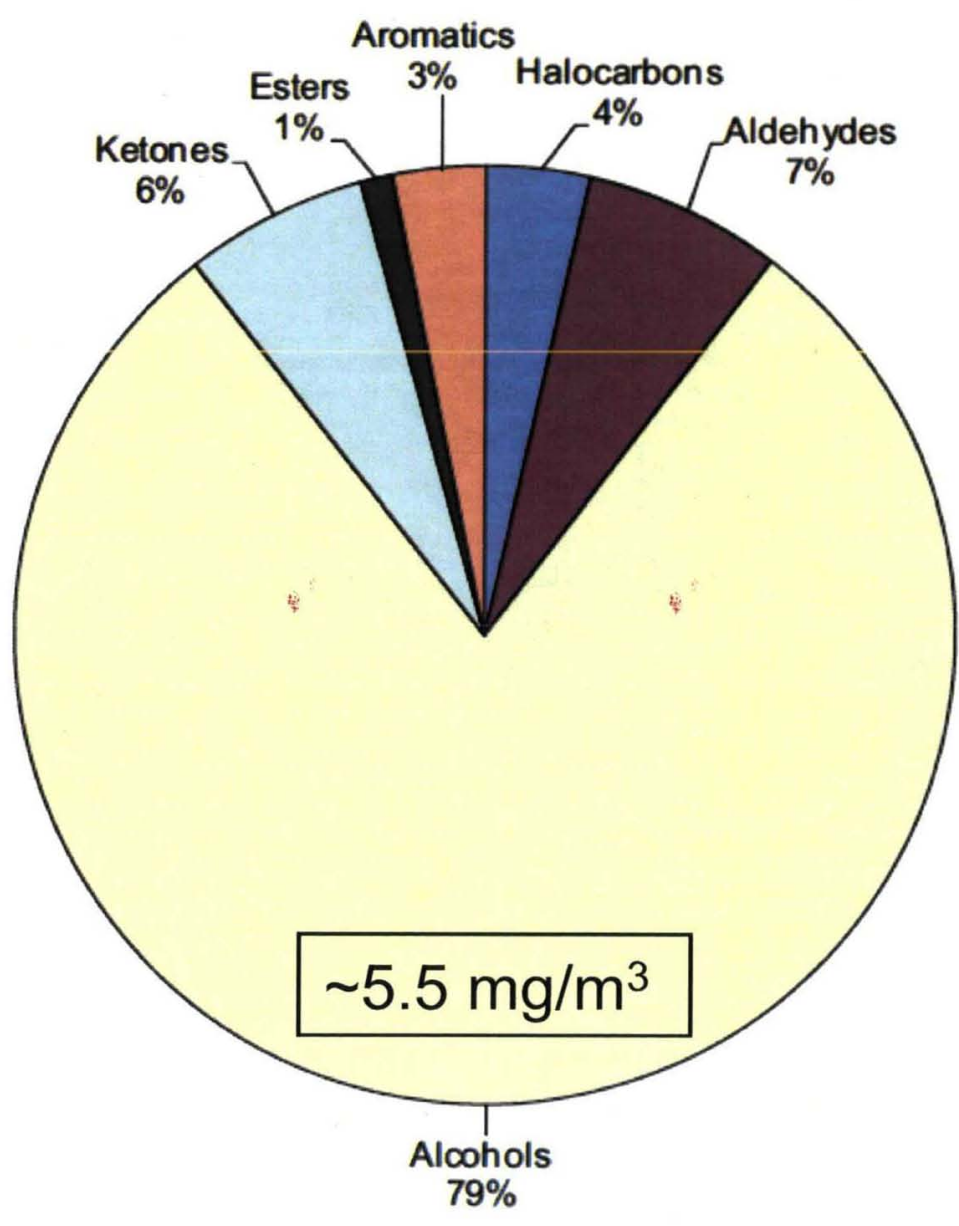




\section{OAIAA :}

\section{Basic Architecture of the ISS Water Recovery System (WRS)}

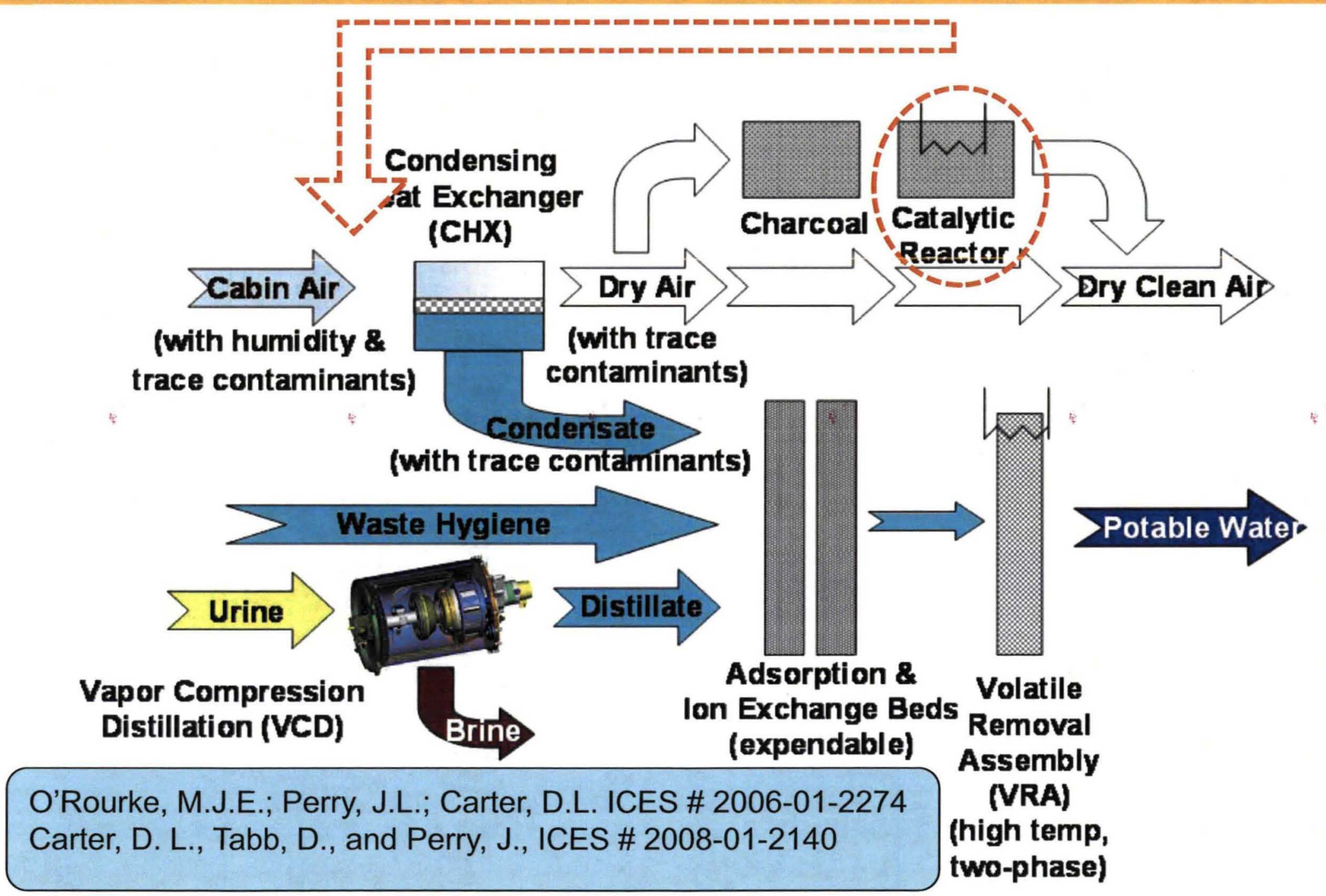




\section{OAIAA}

\section{Photocatalytic Oxidation (PCO)}

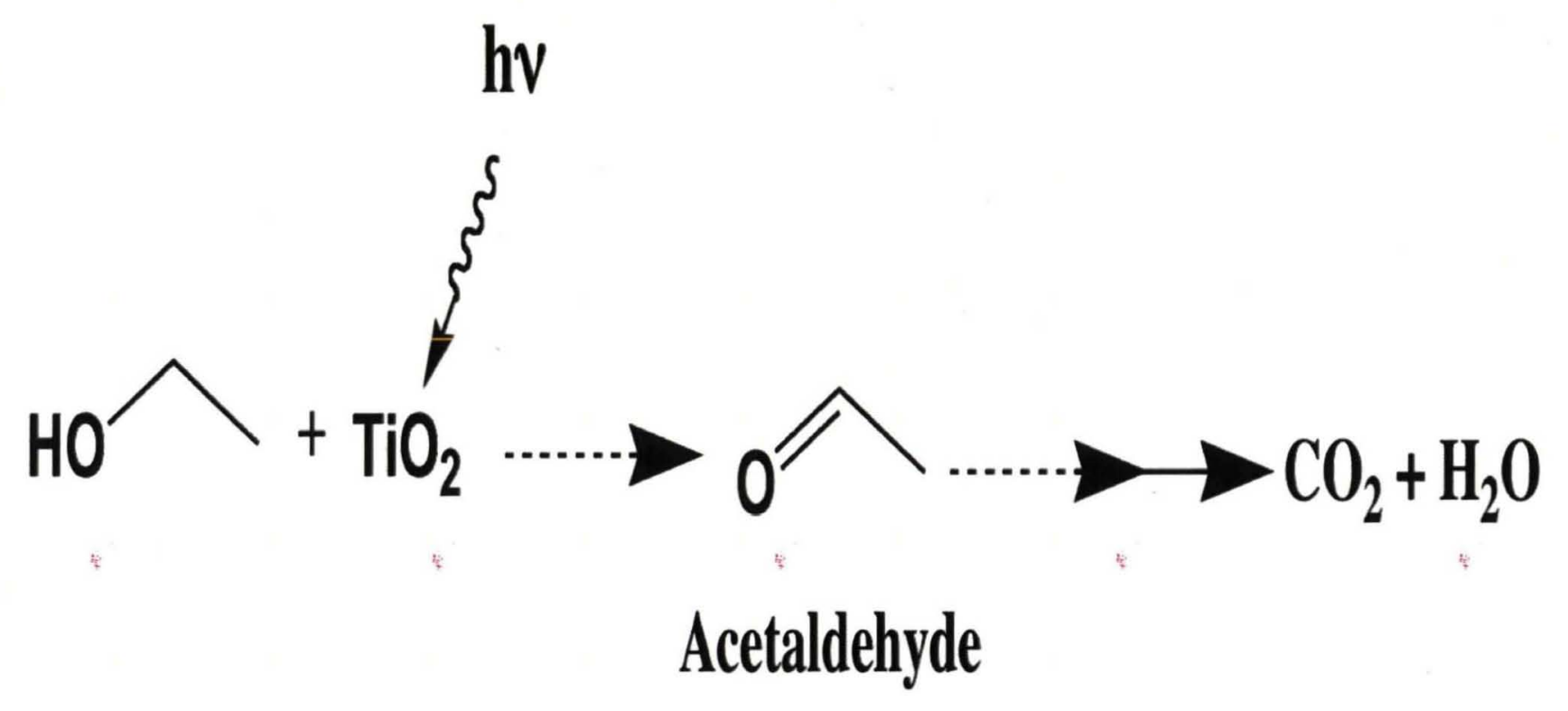

Two predicaments:

$\square$ The requirement of a UV photon source.

$\square$ Incomplete oxidation, resulting in the formation and accumulation of intermediates that are more toxic than the original contaminants. 


\section{(3)}

\section{OAIAA =}

\section{Silica-Titania Composite (STC)}
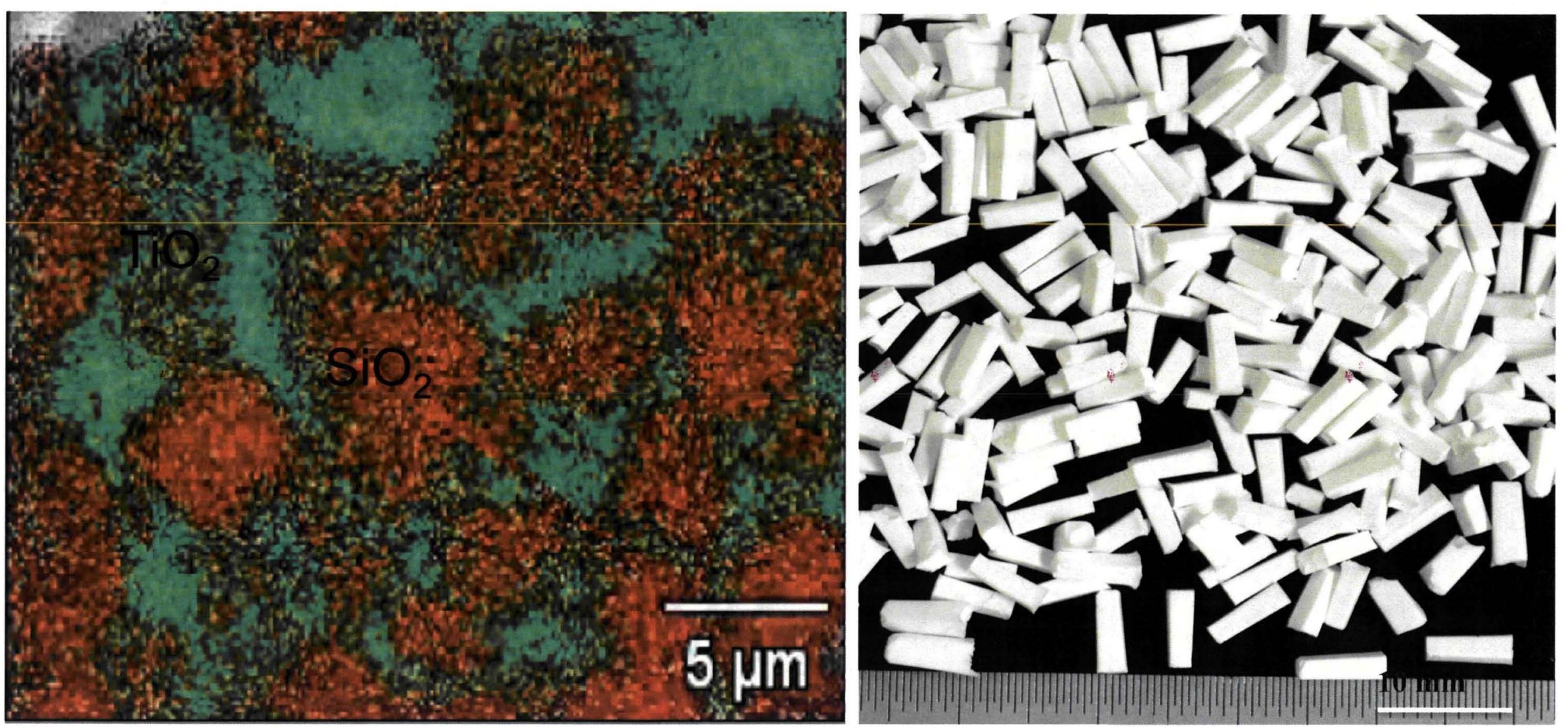


\section{OBJECTIVE}

$\square$ To characterize the performance of STC and examine the impact of following conditions on PCO of ethanol (a representative Polar VOC) and the formation of intermediates.

Light Wavelength: UV-C 254 nm vs. UV-A 365 nm

Light Intensity: 0, 2.7, 5.2 and $7.2 \mathrm{~mW} \mathrm{~cm}^{-2}$

Process Air Humidity (RH): $17 \%, 45 \%$ and $75 \%$

Reactor Operation Mode: Simultaneous vs. Batch PCO

Reactor Temperature: $25^{\circ} \mathrm{C}, 35^{\circ} \mathrm{C}$, and $45^{\circ} \mathrm{C}$ 


\section{OAIAA :}

\section{MATERIALS AND METHODS}

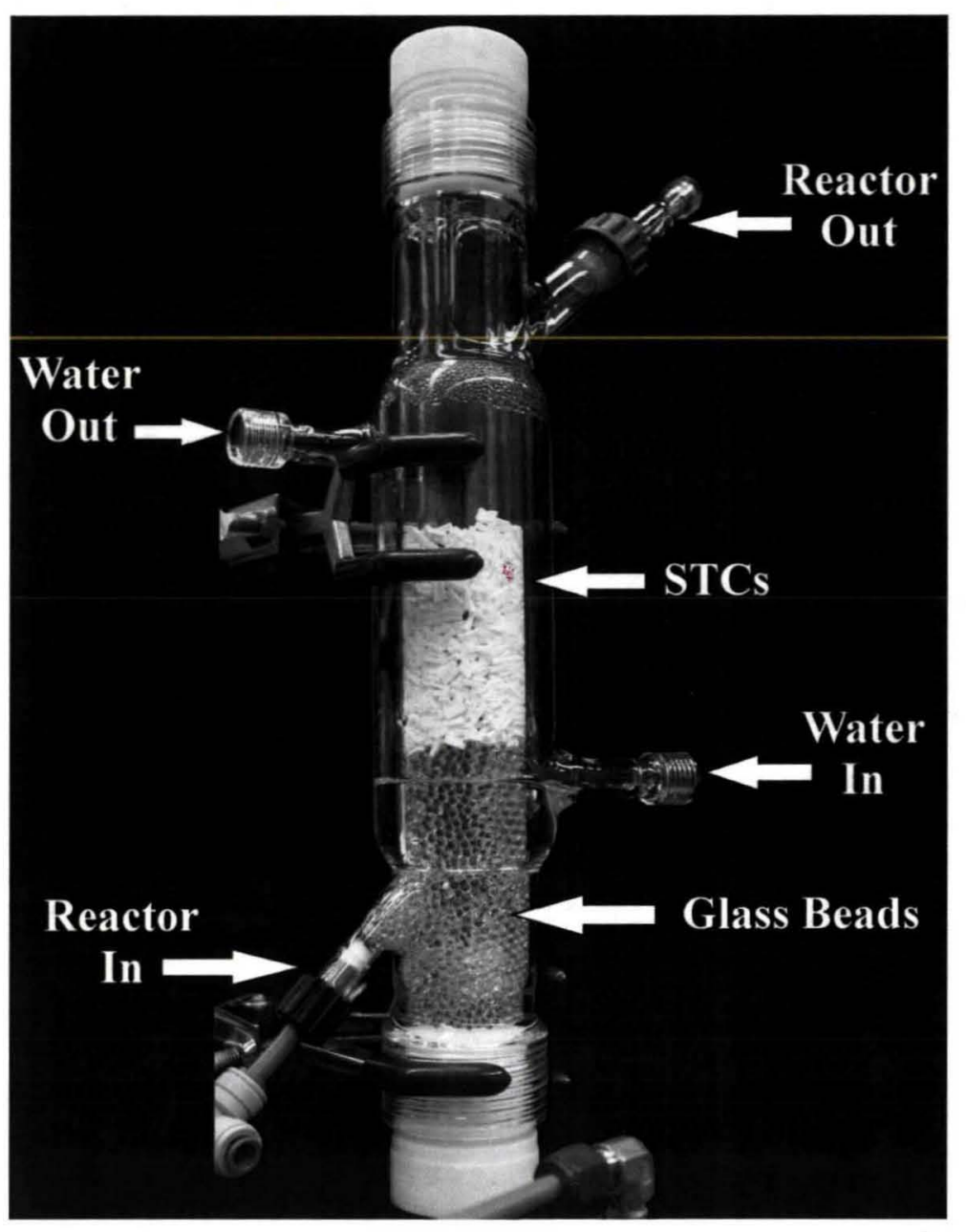

$\square$ Bench-scale annular reactor with $14.6 \mathrm{~g} \mathrm{STC}$

$\square$ Constantly challenged with $50 \mathrm{ppm}_{\mathrm{v}}$ ethanol at $2 \mathrm{~L} / \mathrm{min}$

$\square$ Apparent contact time $0.27 \mathrm{~s}$

$\square$ Single path in three modes: a) dark adsorption, b) simultaneous $\mathrm{PCO}$, and $\mathrm{c}$ ) batch PCO

$\square$ Variables: UV-A vs. UV-C at varying intensity; reactor $\mathrm{T}$, process air $\mathrm{RH}$ 


\section{OAIAA :}

\section{A typical PCO Test Example}

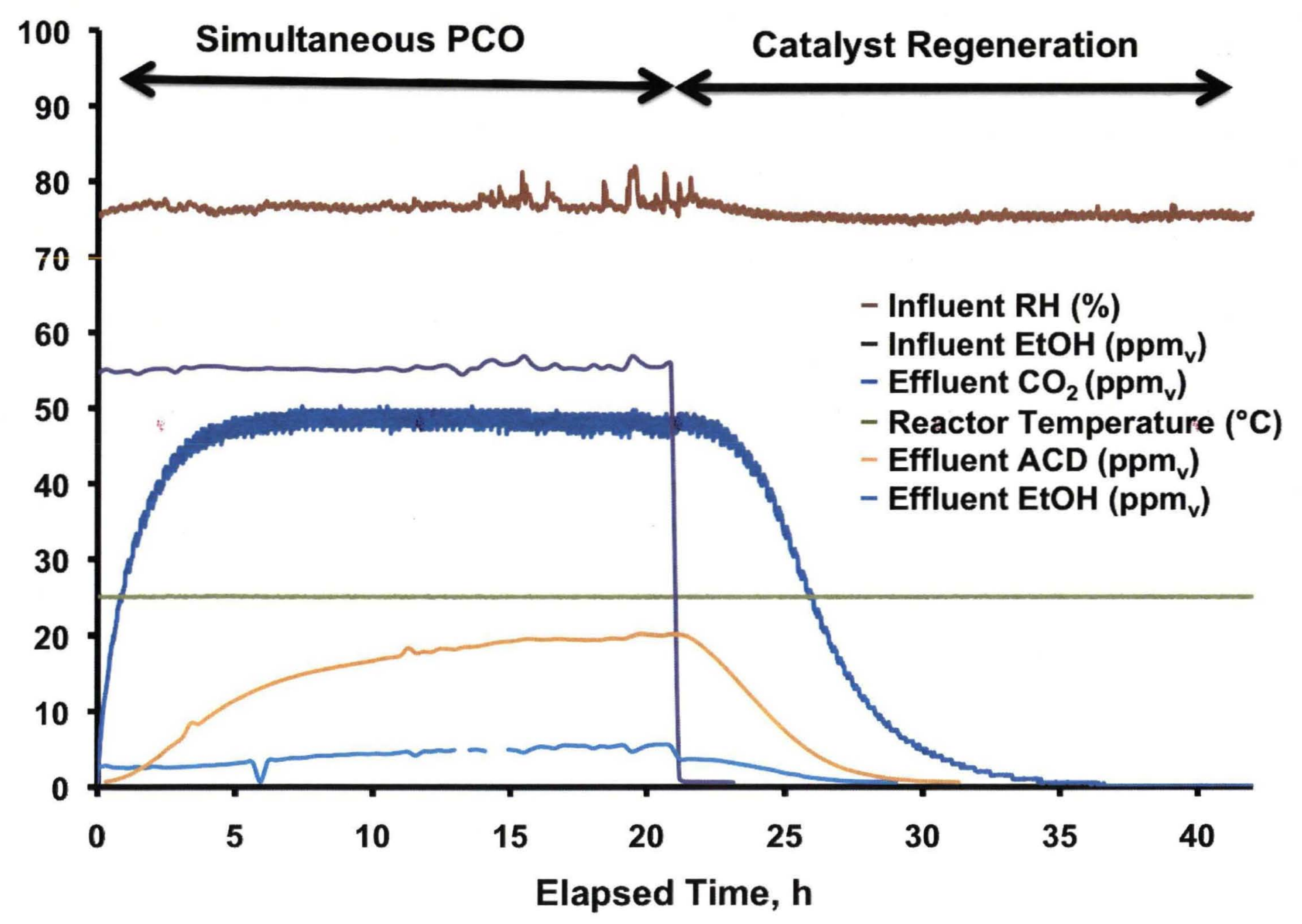




\section{OAIAA :}

\section{Effect of Light Source-Time Course}
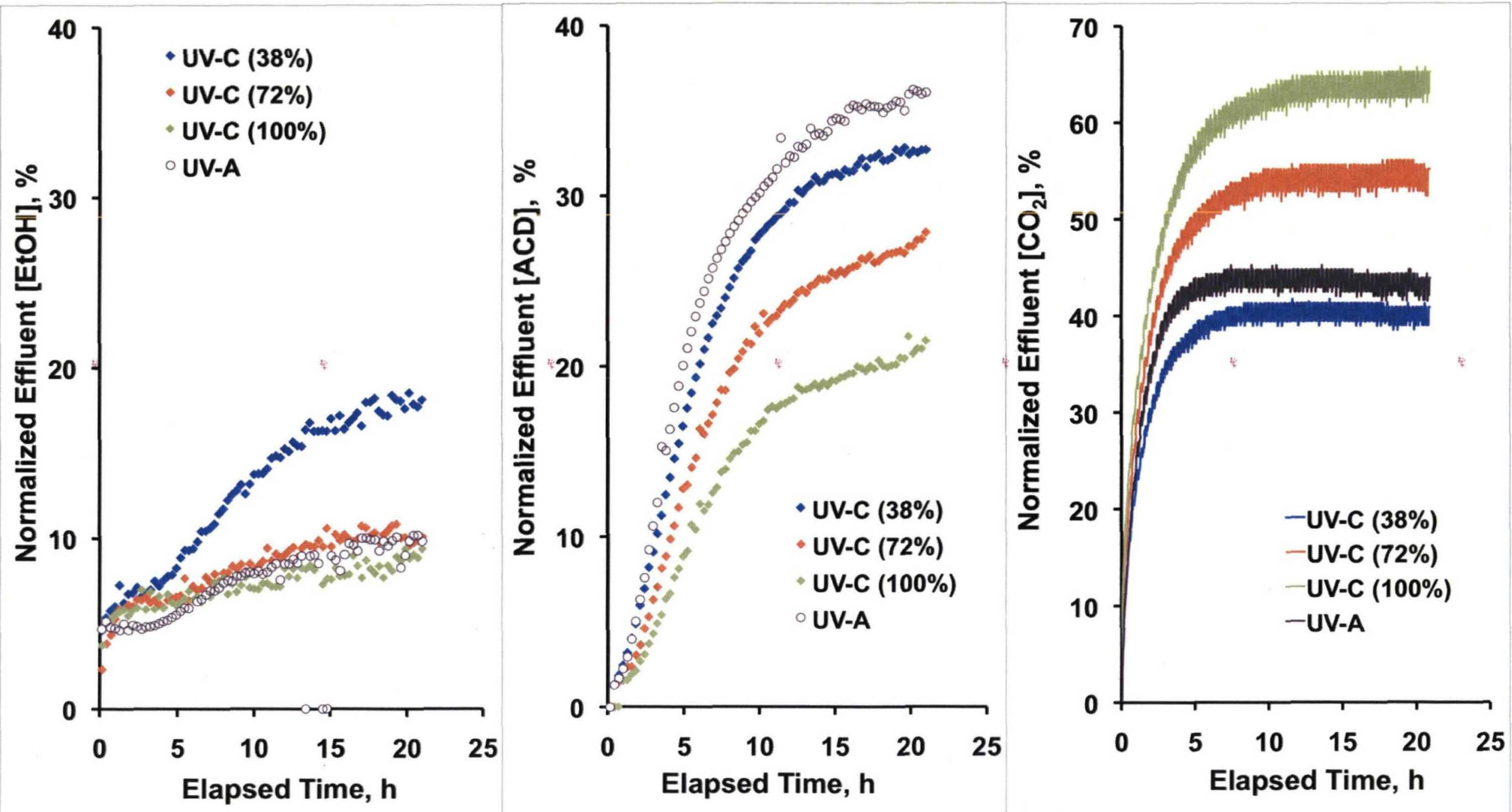


\section{Effect of Light Source-Steady State Parametric}
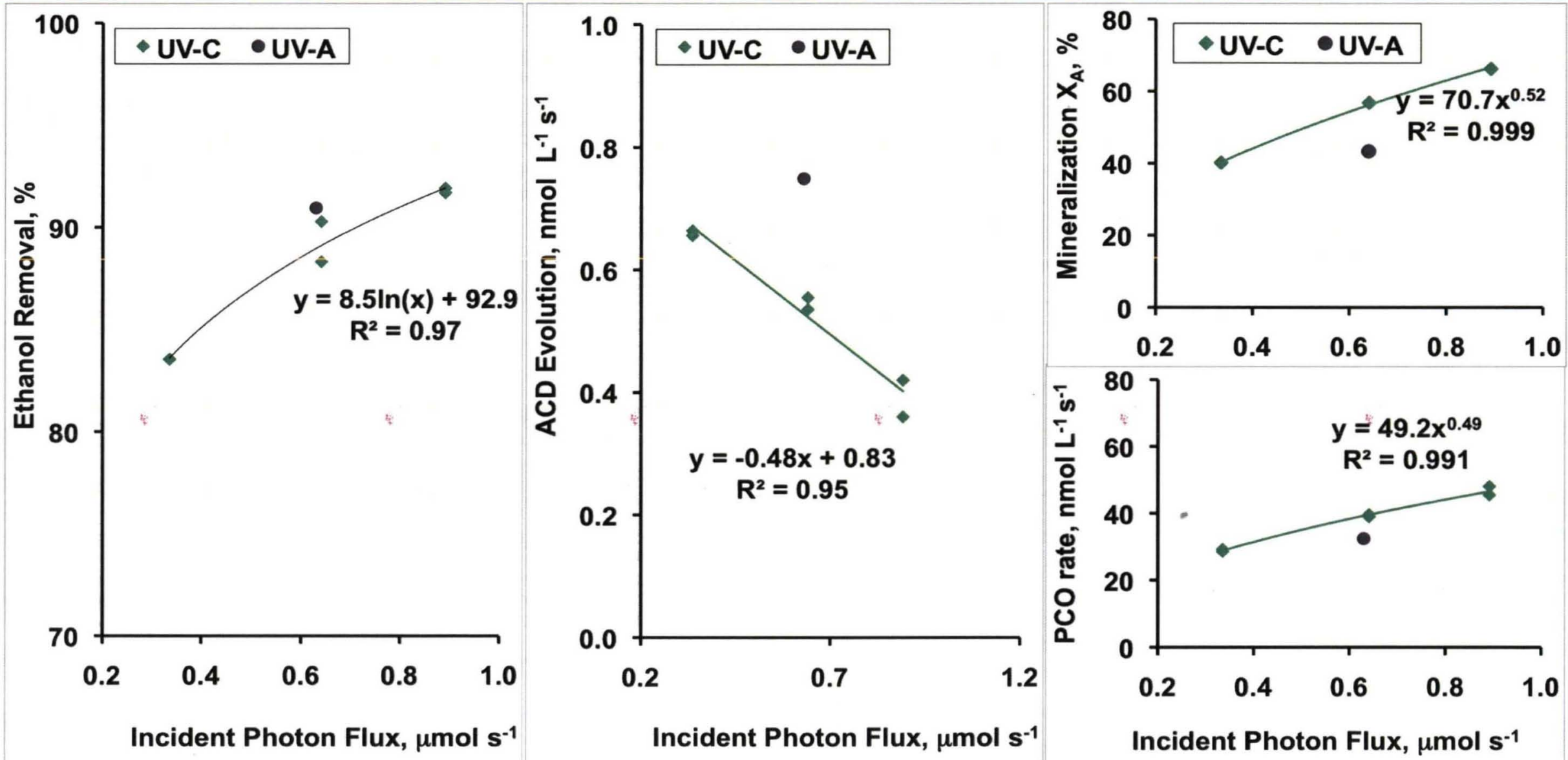

Incident Photon Flux, $\mu \mathrm{mol} \mathrm{s}^{-1}$

EtOH Removal $(\%)=\left(1-\frac{[\mathrm{EtOH}] \text { out }}{[\mathrm{EtOH}] \text { in }}\right) \times 100 \quad X_{\mathrm{A}}=\frac{\left(\left[\mathrm{CO}_{2}\right] \text { out }-\left[\mathrm{CO}_{2}\right] \text { in }\right)}{2 \times[\mathrm{EtOH}] \text { in }} \times 100 \quad \xi=\frac{\text { PCO rate }\left(\mathrm{mol} \mathrm{L}^{-1} \mathrm{~s}^{-1}\right)}{\text { incident photon flux }\left(\mathrm{mol} \mathrm{s}^{-1}\right)}$ 


\section{Acetaldehyde Concentration in the Context of SMAC}

\begin{tabular}{|c|c|c|}
\hline Light Source & $\begin{array}{l}\text { Released ACD in \% of } \\
{\left[[E t O H]_{\text {in }}\right.}\end{array}$ & $\begin{array}{l}\text { Effluent }[A C D] \text { in ppm } \\
\text { when }[E t O H]_{\text {in }}=5 p_{\mathrm{ppm}}\end{array}$ \\
\hline
\end{tabular}

\begin{tabular}{ccc} 
UV-A & 24.8 & 1.20 \\
UV-C $(38 \%)$ & 23.8 & 1.20 \\
UV-C $(72 \%)$ & 18.8 & 0.90 \\
UV-C $(100 \%)$ & 13.3 & 0.70 \\
\hline
\end{tabular}

* The SMAC of acetaldehyde is 2 ppm $_{v}$ for 180 days exposure. 


\section{OAIAA :}

\section{Effect of $\mathrm{RH}_{\mathrm{i}}$ on EtOH Adsorption}



\section{Effect of $\mathrm{RH}_{\mathrm{i}}$ on Simultaneous PCO}



\section{OAIAA :}

\section{Effect of $\mathrm{RH}_{\mathrm{i}}$ on STC's Performance in PCO of Ethanol}
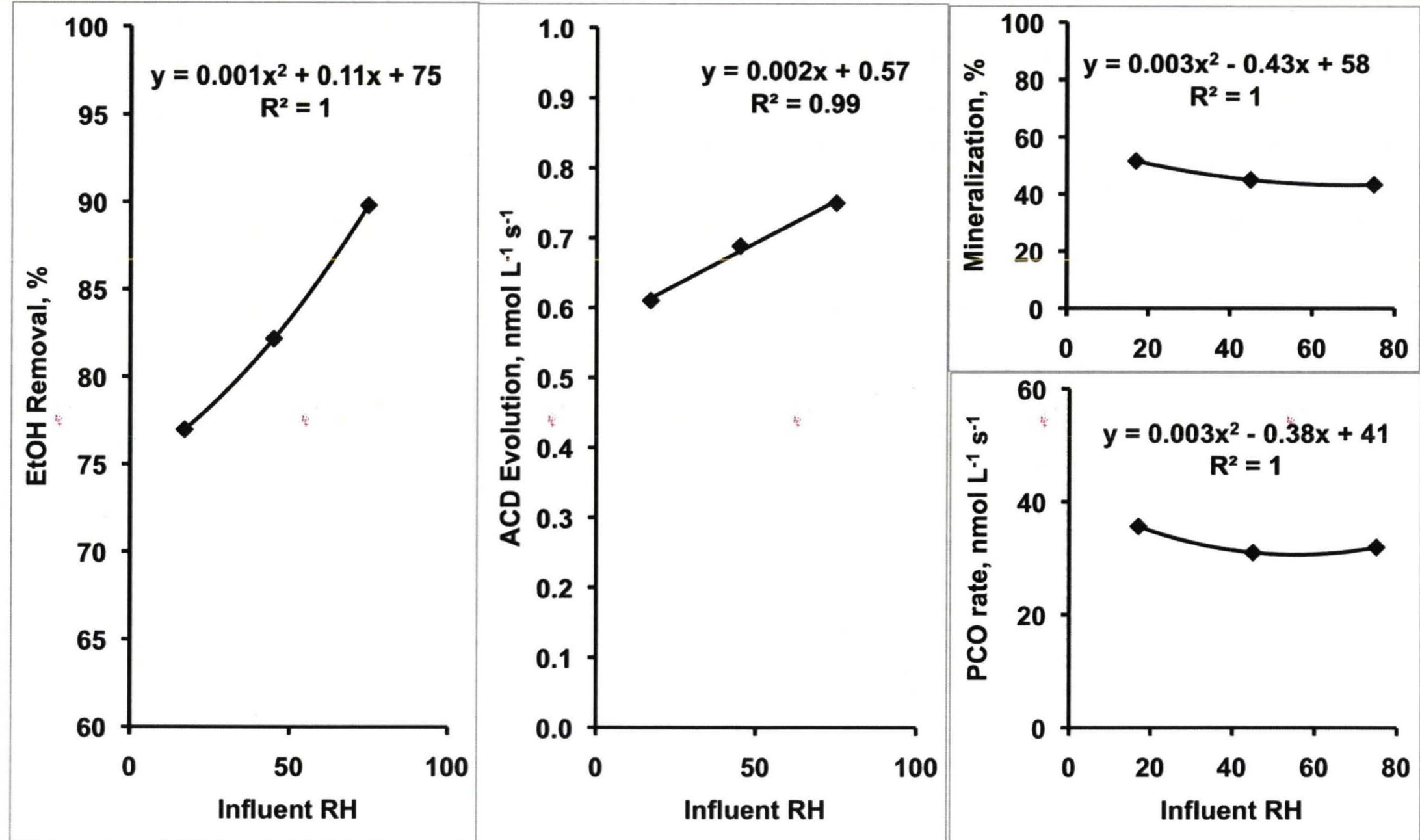


\section{OAIAA :}

\section{Simultaneous vs. Transient PCO}
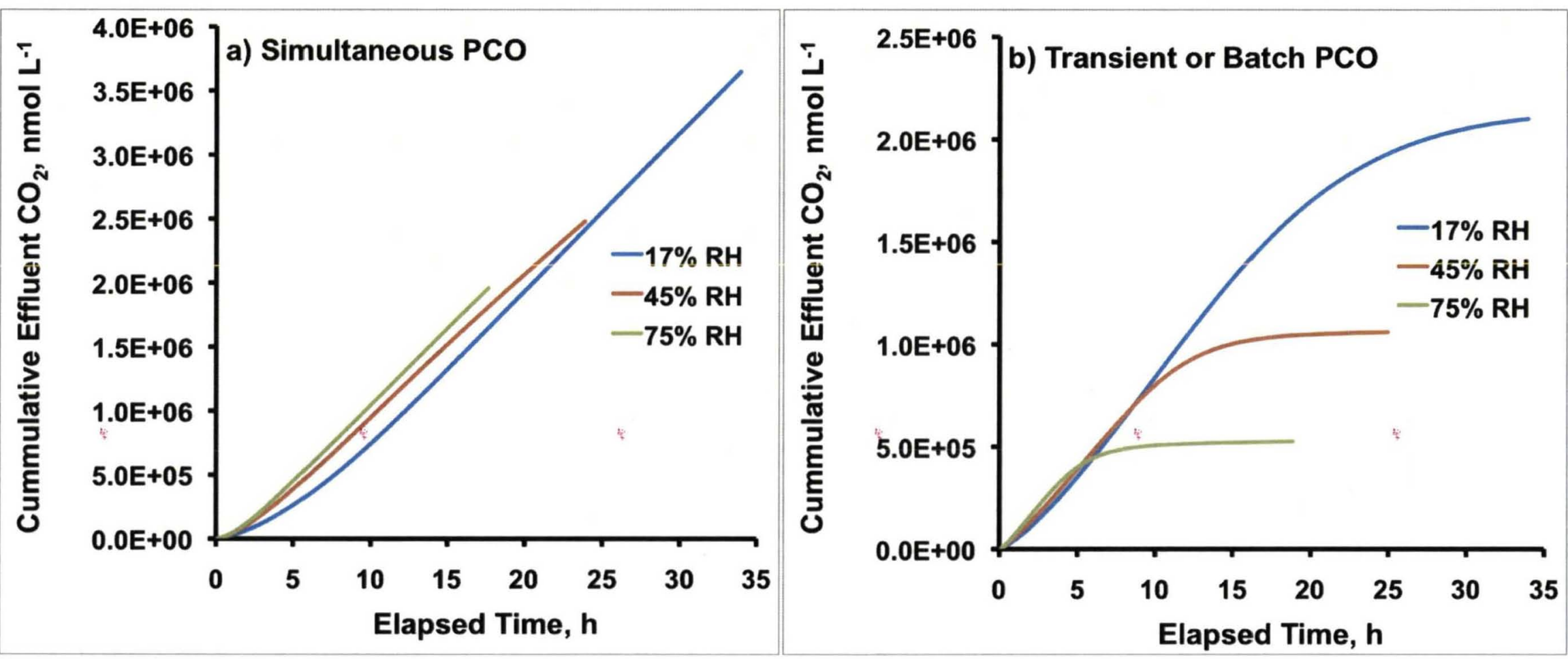

\begin{tabular}{ccccc}
\hline & \multicolumn{2}{c}{ Simultaneous PCO } & \multicolumn{2}{c}{ Transient PCO } \\
\hline $\mathrm{RH}_{\mathrm{i}}(\%)$ & $\mathrm{CO}_{2}$ Rate & $\mathrm{ACD}$ Rate & $\mathrm{CO}_{2}$ Rate & ACD Rate \\
17 & 35.62 & 0.61 & 25.80 & 2.48 \\
45 & 31.00 & 0.69 & 23.38 & 1.69 \\
75 & 31.94 & 0.75 & 24.56 & 1.67 \\
\hline
\end{tabular}




\section{Effect of T on STC's Performance in PCO of EtOH}



\section{OAIAA:}

\section{SUMMARY OF FINDINGS}

EtOH Removal $\propto 8.5 \operatorname{Ln}(q n, p) \times 9.1 \operatorname{LnT} \times 0.001 R H^{\wedge} 2$

ACD Evolution Rate $\propto-0.48(q n, p) \times(-0.017) T \times 0.002 R H^{\wedge} 2$

Mineralization, $X_{A} \propto 70.7(q n, p)^{\wedge} 0.52 \times 1.49 T \times 0.003 R H^{\wedge} 2$

PCO Rate $\propto 49.2(q n, p)^{\wedge} 0.49 \times 0.95 T \times 0.003 R H^{\wedge} 2$

$\begin{array}{lll}\mathrm{q}_{\mathrm{n}, \mathrm{p}} & = & \text { photon flux, molar } \\ \mathrm{RH} & = & \text { relative humidity } \\ \mathrm{T} & = & \text { reactor temperature }\end{array}$




\section{SUMMARY OF FINDINGS}

\section{continued}

$\square$ The UV-C photons proved to be more effective and efficient than UV-A for PCO because of its higher photonic efficiency as well as its capability to reduce acetaldehyde formation.

$\square$ Simultaneous PCO is a preferred mode of operation to batch PCO because it not only has a higher mineralization efficiency, but also has 2-4 times less acetaldehyde depending upon the $\mathrm{RH}$ of process air.

$\square$ There exists competitive adsorption by STC among chemicals and the affinity of chemicals with STC is directly correlated with their hydrophilicity, e.g. Water $>$ Ethanol $>$ Acetaldehyde $>\mathrm{CO}_{2}$.

$\square$ Formation and release of acetaldehyde is inevitable, but none of the scenarios exceeded its 180 day exposure SMAC (2 ppm $\left.{ }_{\mathrm{v}}\right)$. 


\section{ACKNOWLEDGEMENTS}

$\square$ NASA's Exploration Life Support Program - Air Revitalization Element and NASA's ISS Research

$\square$ Mr. Jay Perry at MSFC

$\square$ Dr. Oscar Monje and Dr. Raymond Wheeler at KSC

$\square$ Mr. Lawrence L. Koss at KSC 